\title{
A simple and compact model of defects and non-linear dynamic stiffness of a ball bearing
}

\author{
Mourad Dougdag ${ }^{1, a}$ And Mohammed Ounli ${ }^{2}$ \\ 1 COMENA/CRNB/DTN/Laboratoire des Études Mécaniques, CRNB BP 180 Ain-Oussera, \\ 17200 Willaya de Djelfa, Algérie \\ 2 Département de Mécanique, Faculté des sciences pour l'ingénieur, Université Saad Dahlab Blida, BP 27, \\ Route de Soumâa, Blida, Algérie
}

Received 7 January 2009, Accepted 30 November 2009

\begin{abstract}
This paper presents a modelling study of a ball bearing dynamic behaviour with different defects types, which is part of an investigation related to the modelling of machinery rotating components. Our contribution in this work is a proposition of a five-degree of freedom model describing the nonlinear dynamic behaviour of a ball bearing. The aim is a parametric formulation of the ball bearing stiffness which allows the introduction of the defects characteristics. This approach is a result of an intrinsic structural behaviour making it different from methods which introduce external impulsion to simulate defects. Hence, a more realistic dynamic ball bearing defect simulation is obtained for better use in design and maintenance domain. This simulation can be formulated by two methods. The first, partial contact method, is based on elimination of some ball stiffness. The second one imposes displacement in the system response. Obtained results give response forms similar to standards and to different author's results (theoretical and experimental) found in the literature. The developed model is simple, compact as compared to existing ones and we can express our satisfaction about this promising model.
\end{abstract}

Key words: Modelling / ball bearings / dynamic stiffness / defects / partial contact / imposed displacement / balls scrolling / design / maintenance

Résumé - Modèle simple et compact des défauts et de la rigidité dynamique non-linéaire d'un roulement à billes. Cet article présente une étude portant sur la modélisation du comportement dynamique d'un roulement à billes présentant des défauts. Il constitue une partie d'un ensemble de travaux de modélisation touchant différents organes de machines tournantes. La contribution dans ce travail consiste en la proposition d'un modèle à cinq degrés de liberté décrivant le comportement dynamique non-linéaire des roulements à billes. On aboutit à un formalisme de la raideur qui permet d'introduire les défauts caractéristiques des roulements sous formes paramétriques. Cette approche est issue des caractéristiques intrinsèques de la structure, ce qui la rend différente des méthodes qui simulent l'effet de présence du défaut par un signal d'impulsion. Ce formalisme, en améliorant et en rendant la simulation des défauts plus réaliste, peut être d'une plus grande utilité, dans les domaines de conception et de maintenance des machines tournantes. La simulation des défauts est basée sur deux méthodes. La première consiste à enlever une partie de la raideur globale tout en assurant le contact des billes avec les bagues, c'est la méthode à contact partiel. La deuxième consiste à introduire un déplacement équivalent à la taille du défaut dans la réponse du système, c'est la méthode du déplacement imposé. Les résultats obtenus ont donné des réponses de forme similaire aux standards et aux résultats théoriques et expérimentaux trouvés dans la littérature. Le modèle développé est assez simple et compact comparativement aux modèles existants. On peut, alors exprimer notre satisfaction de ce modèle prometteur dont les aptitudes à introduire plusieurs types d'anomalies ont été avérées.

Mots clés : Modélisation / roulements à billes / raideur dynamique / anomalies / contact partiel / déplacement imposé / défilement de billes / conception / maintenance

${ }^{a}$ Corresponding author: Dougdag_m@yahoo.fr 


\section{Nomenclature}

\begin{tabular}{|c|c|}
\hline$\alpha:$ & angle, \\
\hline$\beta:$ & contact angle of ball with ring, \\
\hline$\delta_{\mathrm{i}}:$ & deflection/deformation, \\
\hline$\delta_{\mathrm{T}}:$ & total deformation, \\
\hline$\phi:$ & load angular position, \\
\hline$\gamma:$ & train (cage) angular rotation, \\
\hline$\varepsilon:$ & radius of curve of ball's housing, \\
\hline$\psi:$ & angle, inner ring tilt angle/y \\
\hline$\varphi:$ & angle $/ x$, ball's position $/ x$ \\
\hline$\varphi_{n}:$ & gap angle between two balls, \\
\hline$\nu:$ & Poisson's ratio, \\
\hline$\theta:$ & inner ring tilt angle/z, \\
\hline$\omega:$ & shaft angular or spin speed, \\
\hline$\omega_{\mathrm{ca}}:$ & cage rotational speed, \\
\hline$a:$ & half contact width, \\
\hline$b:$ & width, \\
\hline$c:$ & damping coefficient, \\
\hline$d_{\mathrm{b}}:$ & ball diameter \\
\hline$d_{\text {ext }}:$ & outer ring diameter in ball housing, \\
\hline$d_{\text {int }}:$ & inner ring diameter in ball housing, \\
\hline$d_{i}:$ & displacement $/ R, X, y$ and $Z$ \\
\hline$d_{\log }:$ & ball housing diameter, \\
\hline$d_{\mathrm{p}}:$ & bearing pitch diameter, \\
\hline$h:$ & gap between rings, \\
\hline$h_{r}:$ & local deformation depth, \\
\hline$L_{\mathrm{C}}:$ & contact width of the (ball/ring), \\
\hline$n:$ & ball number, \\
\hline$m:$ & loaded balls number, mass, \\
\hline$p:$ & ball bearing perimeter, \\
\hline$q_{0}:$ & maximum distributed loading, \\
\hline$q(p):$ & distributed loading along perimeter $p$, \\
\hline$q(r):$ & distributed loading along $r$ \\
\hline$q(z):$ & distributed loading along $z$ \\
\hline$r_{m}:$ & bearing pitch radius, \\
\hline$A_{r}:$ & elementary area according to the axis $r$, \\
\hline$E_{i}:$ & Young's modulus for (ball, ring), \\
\hline$F_{i}:$ & force $/ r, t, x, y \& z$ \\
\hline$F_{m}:$ & maximum force, \\
\hline$F_{r}:$ & radial force, \\
\hline$K_{r r}:$ & radial stiffness, \\
\hline & mass, moment, \\
\hline NR, NT, NB: & shaft, cage \& ball speed \\
\hline$R, R_{\mathrm{b}}$ & ball radius, \\
\hline$R_{\mathrm{a}}:$ & shaft radius, \\
\hline$R_{1 \mathrm{e}}:$ & external inner ring radius, \\
\hline$R_{2 i}:$ & internal outer ring radius, \\
\hline$R_{\log }:$ & ball's housing radius, \\
\hline $\mathrm{T}:$ & cycle, \\
\hline$W:$ & load rotating vector. \\
\hline
\end{tabular}

\section{Introduction}

The mechanical behaviour modelling of this device part is mainly based on the stiffness calculation which is obtained by the local $[1,2]$ and global [3] ball bearing deformations under various loadings.

The ball bearing took importance since Palmgren [4] work, Harris [5] and Eschmann [6]. Their purpose was to describe the vibration transfer towards the structure. In fact, the ball bearings introduce several sources of nonlinearities associated with the mechanical gaps and the Hertzian contacts between the rolling balls and balls raceways.

It is accurate to note that the suggested model is based on a stiffness matrix terms linearization around an equilibrium position corresponding to the static ball bearing loading. A simplified method consists to introduce radial stiffness springs which are often isotropic; it is a concentrated parameters model.

But this approach does not consider the coupling between bending and tension-compression. Kraus [7] measures the axial and radial stiffness with harmonic forces and Drago [8] tried to introduce angular stiffness according to shaft bending planes. Rajab [9] introduced the coupling and Young [10] has included the axial load effect. This trend was validated by Lim [11] and De Mull [12]. This last author improved Lim's model. These models reveal the gyroscopic moment, knowing that before Fukata and Coll. [13] suggest a consisting model which includes balls inertia. After that, works have oriented to take into account the geometrical defects, but models stay linear Yhlan [14]. Choi [15] and Bourdon [16] adapted the ball bearing model to the finite-element formalism by introducing the ball elements and considering the ring deformation.

The defects modelling was introduced by authors like McFadden (1984, 1985) [17] and Briant [18]. They presented the anomalies as an impulsion force form.

Our contribution is to propose an analytical model of five-degrees of freedom describing the nonlinear dynamic behaviour of the bearings by considering load level on balls, cage motion (ball scrolling) and load rotating vector. This model uses:

1. Palmgren's technique of deformation calculus [4];

2. Rajab's technique of stiffness matrix elements calculus $[9]$;

3. load model; and

4. dynamic model.

The obtained model will lead to a formulation which introduces the ball bearing defects characteristics under parametric forms. Defect simulation is obtained by handling stiffness formula. It can be formulated in two methods. The first, partial contact method is based on elimination of some ball stiffness while ensuring contact between others balls and rings. The second one is to impose an equivalent displacement of the defect size, to the system response.

\section{Theoretical model}

Different rolling bearings technologies are used in rotating machines depending on the application. Due to their complexity and their diversity, this study focuses only on deep-groove ball bearing.

The theoretical development aims to calculate ball bearing stiffness; which requires knowledge of contact scheme, elasticity laws and an adequate loading model. 


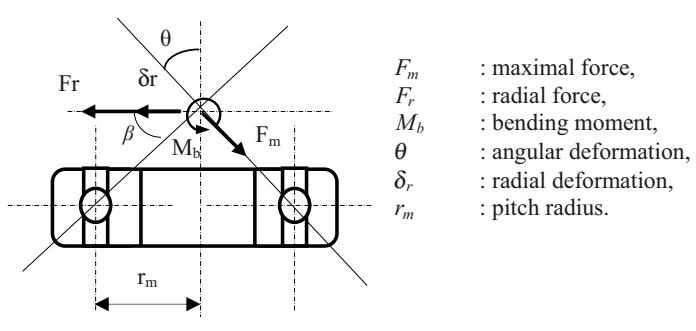

Fig. 1. Diagram of maximum force applied to the ball bearing.

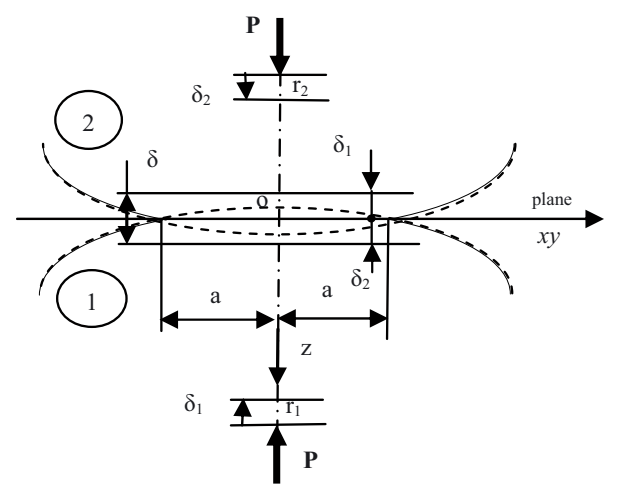

(a)

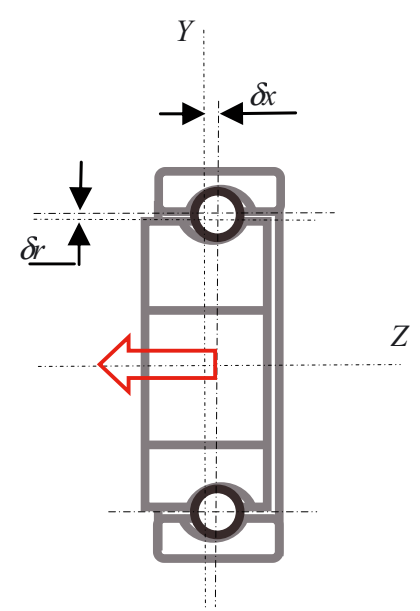

(b)

Fig. 2. (a) Deformation according to Hertz law [19,20]. (b) Calculation of axial and radial deformation by Palmgren's technique.

The concepts and details concerning the geometrical characteristics, physics and kinematics could be found in $[2,5,21,22]$.

\subsection{Stiffness calculation}

The stiffness evaluation is based on the Rajab's model [9] (Fig. 1). Thus, deformation and the corresponding loads are calculated, in order to deduce the stiffness into quasi-static mode.

Deformations due to the ball contact with the higher and lower raceways (Fig. 2) are calculated according to Hertz law [19,20] and using Palmgren's model [23].

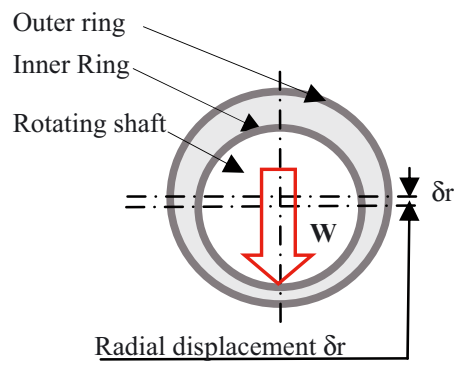

(a)

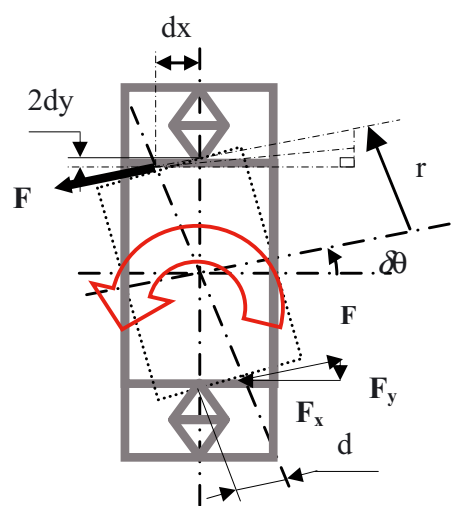

(b)

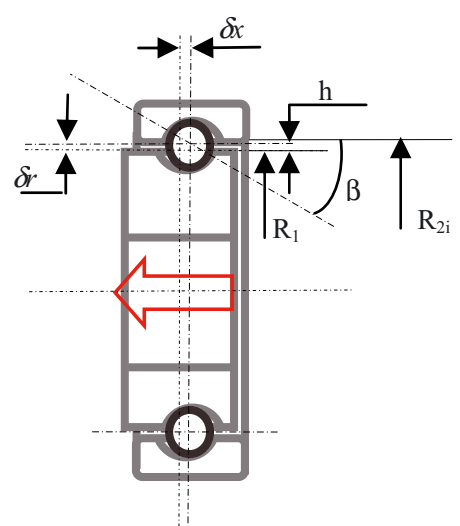

(c)

Fig. 3. (a) Total bearing radial deformation model diagram $\delta r$. (b) Angular deflection model $\delta \theta$. (c) Axial deformation model $\delta x$.

\section{Rajab's Model}

Rajab [9] introduces the coupling between radial displacement and rotation according to the bending plane. The stiffness is calculated by resolving the nonlinear equation of the system under static equilibrium. The inner ring is loaded by a radial force $\left(F_{r}\right)$ and a bending moment $\left(M_{b}\right)$, whereas the external ring is fixed. Obtained rigidity is a matrix of order two and is given as follows:

$K_{r r}=F_{r} / \delta_{r} K_{r \theta}=F_{r} / \theta \quad$ and $\quad K_{\theta r}=M_{b} / \delta_{r} K_{\theta \theta}=M_{b} / \theta$

Rajab's procedure was validated by Young [10] experiments. 


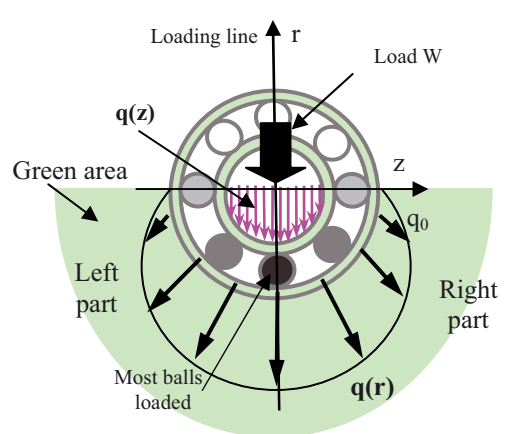

(a)

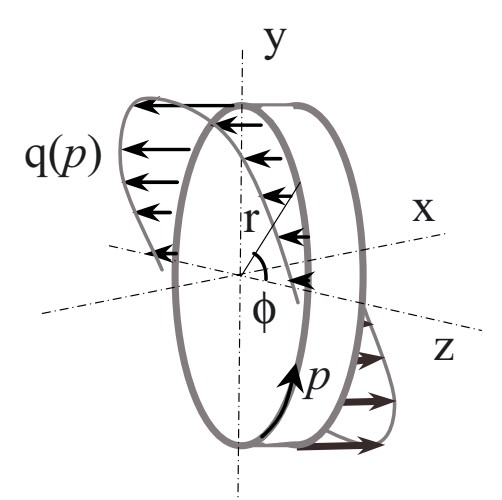

(b)

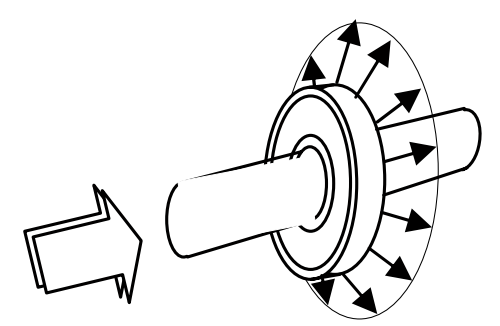

(c)

Fig. 4. (a) Load distribution model on balls before contact $(q(z))$ and after contact $(q(r))$. (b) Torque distribution model on inner ring. (c) Axial load distribution model.

\section{Palmgren's model}

Based on Hertz law (Fig. 2a) Palmgren [23] established analytical-behaviour models of ball bearings loaded in axial and/or radial direction from a "force-displacement" point of view. The Palmgren's technique estimates radial and axial deformations as presented in Figure 2b [24].

The principal bearing deformations and loading modes considered are sequentially illustrated in Figures 3 and 4; some of them require the development of a model.

Due to the important time-volume of the analytical stiffness calculations; only the radial stiffness was considered in this study.

The stiffness calculation is based on the following steps:

- calculate Palmgren's local-deformation using his model [23];

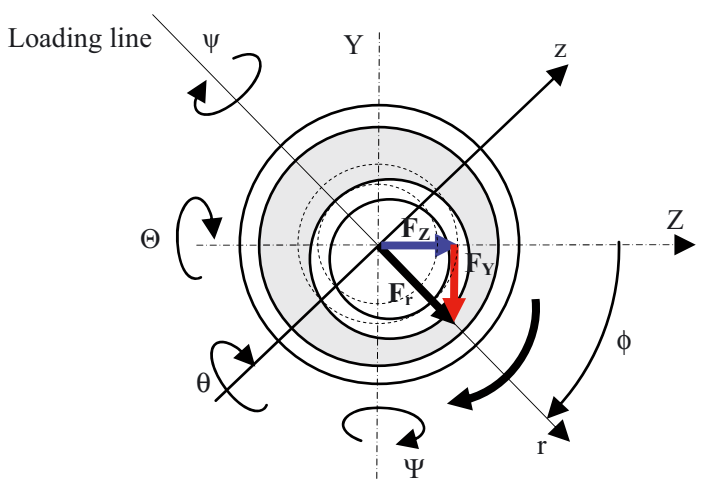

Fig. 5. Rotating coordinate system at equilibrium position.

- determine the loads which generated these deformations; and

- calculate the stiffness using Rajab's technique [9].

The stiffness matrix calculation is obtained by combination of the loads and deformations [9] according to the loading condition considered in Figure 5 . It is given in polar coordinate system $(r, x, z, \theta, \psi)$ which turns around axis $x$ as well as in a in fixed Cartesian coordinate system $(x, Y, Z, \Psi, \Theta)$ as shown in Figures 5 and 6. Switching from polar to Cartesian coordinate system, an angular transformation is needed by introducing a rotational angle $(\phi)$ around $x$ axis. The stiffness could be written as follows:

$$
\left[k_{5 x 5}\right]=\left[\begin{array}{ccccc}
K_{r r} & K_{r x} & K_{r z} & K_{r \psi} & K_{r \theta} \\
& K_{x x} & K_{x z} & K_{x \psi} & K_{x \theta} \\
& & K_{z z} & K_{z \psi} & K_{z \theta} \\
& \operatorname{sym} & & K_{\psi \psi} & K_{\theta \theta} \\
& & & & K_{\theta \theta}
\end{array}\right] \&
$$

"Rotating Polar coordinate system"

$$
\left[k_{5 x 5}^{*}\right]=\left[\begin{array}{ccccc}
K_{Y Y} & K_{Y x} & K_{Y Z} & K_{Y \Psi} & K_{Y \Theta} \\
& K_{x x} & K_{x Z} & K_{x \Psi} & K_{x \Theta} \\
& & K_{Z Z} & K_{Z \Psi} & K_{z \Theta} \\
& \text { sym } & & K_{\Psi \Psi} & K_{\Psi \Theta} \\
& & & & K_{\Theta \Theta}
\end{array}\right]
$$

"Fixed Cartesian coordinate"

The transformation formula is $\left[k^{*}\right]=[T][K]\left[T^{t}\right]$, where $[T]$ is expressed as follows:

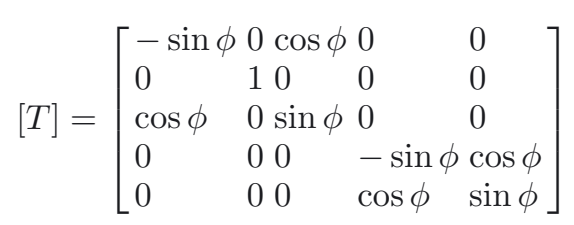

\subsection{Simple machine modelling}

The adopted model for ball bearing is illustrated in Figure 6 . It is mainly modelled by springs in $(x, Y, Z, \theta$, $\psi)$ axes. 

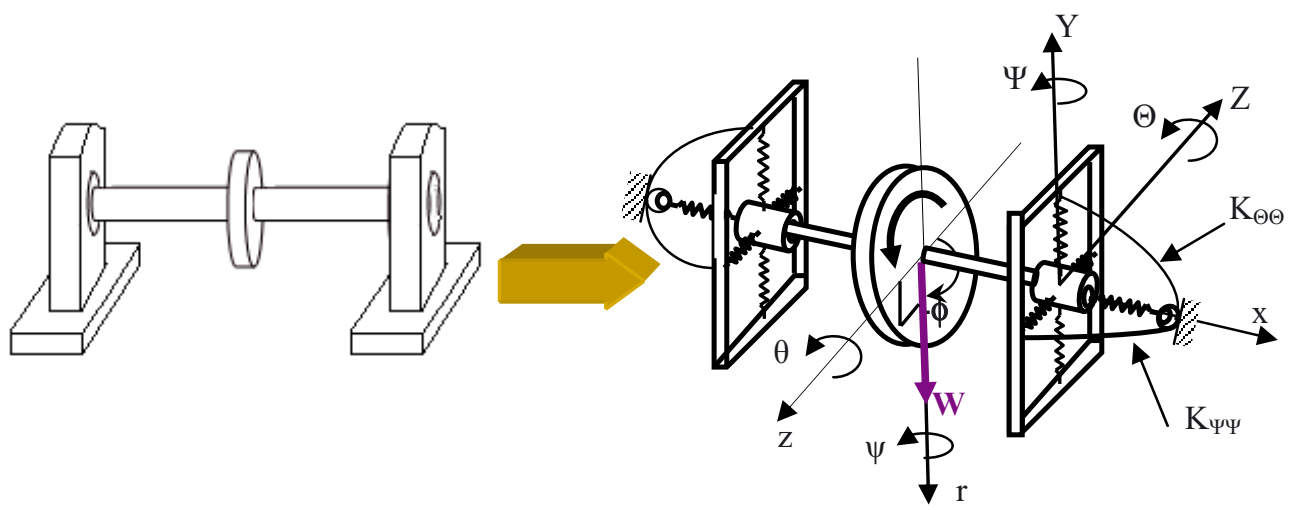

Fig. 6. Ball bearing modelling with principal springs.

Table 1. Palmgren's formula.

\begin{tabular}{cc}
\hline \multicolumn{2}{c}{ Bearings types } \\
\hline Loads on rolling elements & $Q=\frac{5 F_{r}}{i n \cos \beta}$ \\
balls & $\delta_{r}=0.0020 Q^{\frac{2}{3}} d_{b}^{-\frac{1}{3}}$ \\
rollers & $\delta_{r}=\frac{0.0006}{\cos \beta} l_{a}^{-0.8} Q^{0.9}$ \\
\hline
\end{tabular}

A number of hypotheses have been made and are listed below:

- The following data were not considered:

- interactions due to the balls train (cage) and

- rings elastic deformation,

- Bearing contact angle $\beta=0$,

- The bearing clearance was considered,

- The stiffness calculation was done in the polar coordinate system which is attached to the rotating loading vector,

- The initial rotating loading vector was set at the position of $\phi=\frac{\pi}{2}$,

- Balls' mass inertia was taken into account.

The stiffness calculation is done as follows:

- Results presented in Table 1 are based on Palmgren's work $[23,25]$.

with: $\delta_{r}$ : radial displacement $[\mathrm{mm}], F_{r}$ : radial load [daN], $d_{b}$ : element diameter $[\mathrm{mm}]$, la: roller's length $[\mathrm{mm}], n$ : element's number, $i$ : element's row number and $Q$ : maximal load applied on element [daN].

- Force unit is converted to Newton and displacement one to meter, deformation becomes:

$$
\delta_{r}=\left[10^{-4} \frac{0.0020}{(\cos \beta)^{\frac{2}{3}}}\left(\frac{5}{10}\right)^{\frac{2}{3}}\right] F_{r}^{\frac{2}{3}} d_{b}^{-\frac{1}{3}}(i n)^{-\frac{2}{3}}
$$

with $\beta=0$.

- This gives the following form:

$$
F=K \delta^{3 / 2}
$$

where $K$ is a stiffness factor.

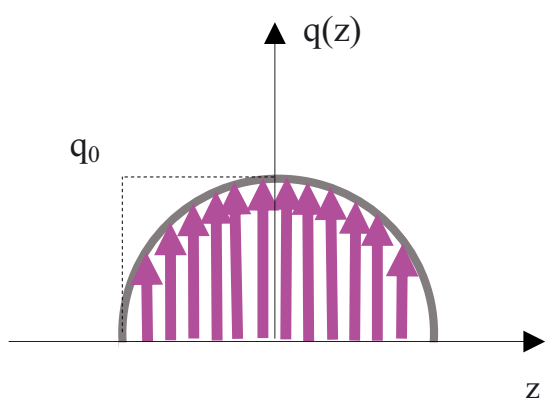

(a)

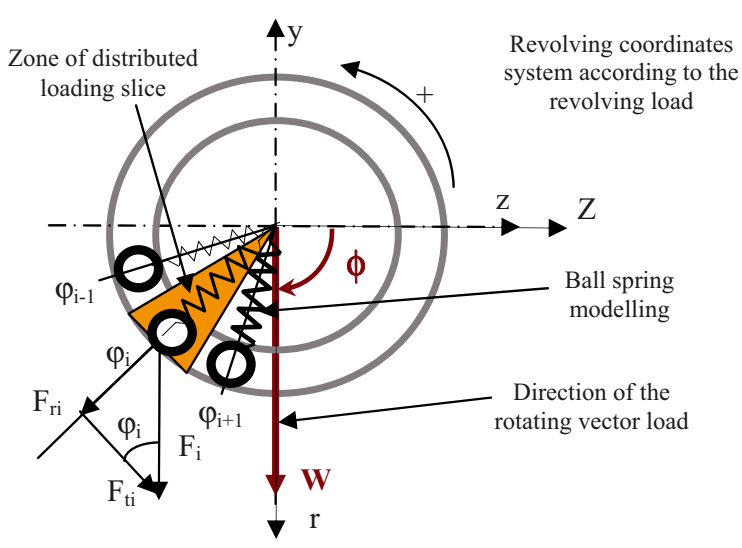

(b)

Fig. 7. (a) Force distribution on loaded balls before contact. (b) Ball's radial loading model.

- Distributed loading slice $[-R,+R]$ in Figure 7a encloses loaded balls, before contact, is expressed by:

$$
q(z)=q_{0} \frac{\sqrt{R^{2}-z^{2}}}{R}
$$

- Variable change of $z$ is $R \cos \varphi$ allow getting distributed loading slice $\left[\varphi_{i}, \varphi_{i+1}\right]$ encloses one ball Figure 7b, as:

$$
q(\varphi)=q_{0} \sqrt{1-\cos ^{2}(\varphi)}=q_{0} \sin \varphi
$$




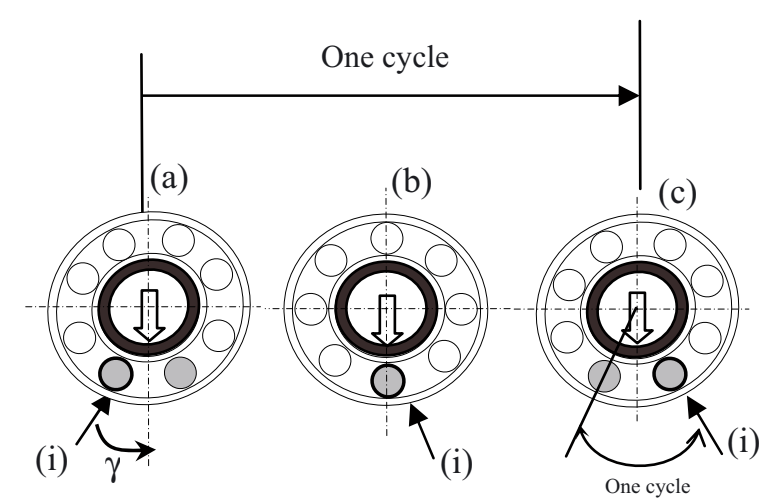

Fig. 8. Balls scrolling with cage rotation (a \& c) two balls in the loading line, (b) one ball in the loading line.

- The total loading $F_{i}$ applied to $i$ th ball is:

$$
F_{i}=L c \int_{z_{i}}^{z_{i+1}} q(z) \mathrm{d} z=L c R q_{0} \int_{\varphi_{i}}^{\varphi_{i+1}}-\sin ^{2} \varphi \mathrm{d} \varphi
$$

- After the resolution of Equation (4) for $\varphi_{i+1}=\varphi_{i}+$ $\left(\varphi_{n}=2 \pi / n\right)=\varphi_{i}+2 \pi / n$ and $q_{0}=\frac{2 F}{R L_{c} \pi}, F_{i}$ becomes:

$$
F_{i}=\frac{F}{2 \pi}\left[\sin 2\left(\varphi_{i}+\pi / n\right)-\sin 2\left(\varphi_{i}-\pi / n\right)-4 \pi / n\right]
$$

- The radial force is defined by:

$$
F_{r i}=\left|F_{i}\right| \sin \varphi_{i}
$$

- The law which links loads to deformations [23] is expressed as follows:

$$
K_{r r}^{(b)}=\frac{\mathrm{d} F_{r}}{\mathrm{~d} \delta_{r}}
$$

Total stiffness calculation introduces effects of balls scrolling, load level applied on each ball and load rotating vector. The stiffness becomes dynamic and nonlinear.

\subsection{Dynamic stiffness}

\subsubsection{Balls scrolling and load level}

Figure 8 shows the main positioning state of the balls for one rotational cycle and Figure 9 illustrates the level of load applied on each ball. Darker shades imply higher load. Cage rotation with balls (balls scrolling) causes change of balls distribution; two cases appear: case of one ball and case of two balls in the loading line.

Based on the loading level applied to the balls, only half of balls are taken into account (green area in Fig. 4a).

Suggested formula with previous factors may take the following form:

$$
K_{r r}(\gamma)=\sum_{i=1}^{m} / K_{r r}^{(b i)} \cos \left(\gamma_{i}-\phi\right) /
$$

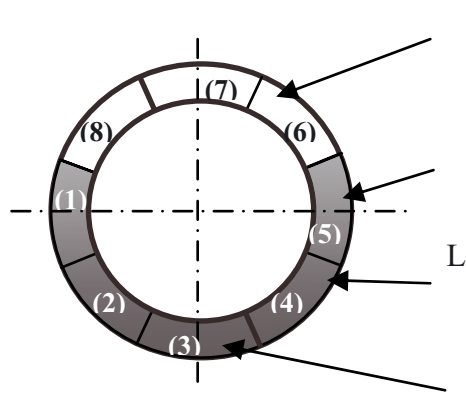

Unloaded

$(6,7$ and 8$)$

Partially loaded

(1 and 5)

Loaded (1, 2, 3 and 4)

Most loaded ball (3)

Fig. 9. Level of load applied on balls by sectors.

with: $\gamma_{i}$ is the (i)th ball angular position (Fig. 8), $\gamma_{i}=$ $\gamma_{i-1}+\varphi_{n}$ where $\varphi_{n}=2 \pi / n, K_{r r}^{(\mathrm{bi})}$ : ball stiffness is considered where $\gamma_{i}$ is in the first half of bearing and not considered in the other half, $\gamma=\omega_{\text {ca }} t+\gamma_{0}$ where $\gamma_{0}$ : initial position each ball, $\phi=\omega t+\phi_{0}$ where $\phi_{0}$ : initial position of rotating loading vector and $m$ : the loaded ball number $\left(m \approx \frac{n}{2}\right)$.

Formula (8) choice can be justified by the following arguments: firstly, the radial forces expressed in formulas $(5,6)$ use sinus function in range $[0, \pi]$ covering a half of balls (see Figs. 4a, 7a, 15), secondly, the radial distance between shifted ring and fixed one is expressed also with sinus function, finally, the loading line could be considered as reference of most loaded ball.

Several authors use a similar form as Estocq [24] to express the balls deformation according to the angular position.

\subsection{Dynamic model}

Theoretical dynamic calculation of the ball bearing, under normal running conditions, uses two models. The first model is a one degree of freedom (1 DOF), Figures 10 and 11, used to simulate major case studies. The second one is two degrees of freedom (2 DOF), Figures 12 and 13, used to introduce shaft effect.

The differential equation of motion has the following shape:

$$
[M]\{\ddot{X}\}+[C]\{\dot{X}\}+[K(t)]\{X\}=\{f(t)\}
$$

The stiffness $K(t)$ can be expressed by:

$$
K(t)=K_{\max } g(t)+K_{\min }
$$

where: $g(t)$ is the nonlinear function of the $K$ variation over time. $C$ is the ball damping factor.

Indeed, the rigidity variation is characterised by two states as shown in Figure 8. That makes a curvilinear stiffness variation between a maximum and minimum value.

When the dynamic model and the total stiffness are obtained, the nonlinear differential equation (9) resolution can be done by several methods. The WilsonTeta [26] and Newmark [27,28] step by step method are chosen. With these methods, the time step $\Delta T$ is calculated by subdividing time cycle between two successive 


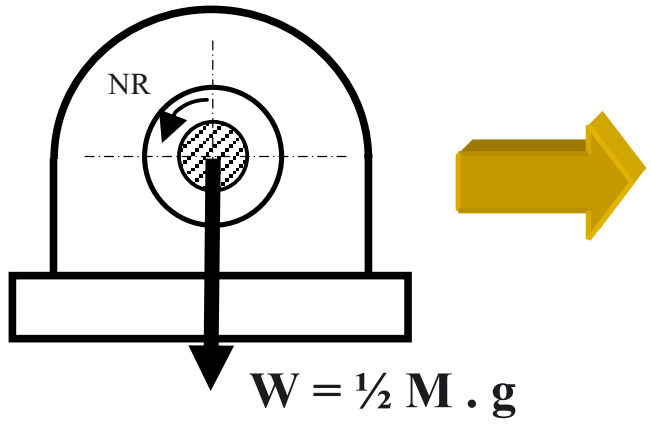

Fig. 10. Bearing dynamic model of one DOF.

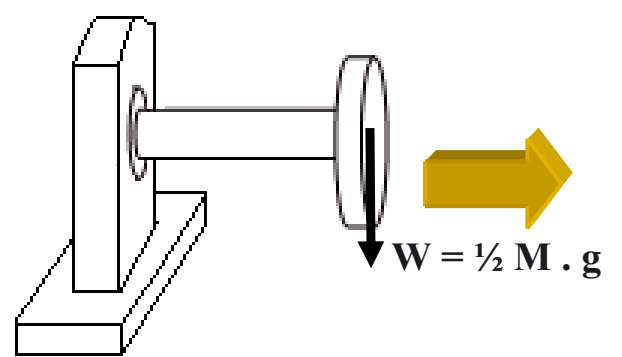

Fig. 12. Symmetric bearing dynamic model of two DOF.

balls positions corresponding to angle range $\left[\varphi_{i}, \varphi_{i+1}\right]$ by 100 or more steps as seen in Figures $7 \mathrm{~b}$ and $16 \mathrm{~b}$.

\subsection{Defects modelling}

The ball bearing defect modelling [29-31] is obtained by introducing some special parameters into Equation (8). For example, some defect cases are presented in Figure 14 as cavity, bump (a small metal extrusion, impurity or scaling), or a harder zone on the ring race.

Most of these defects can be modelled by introducing some parameters. For example to simulate cavity, the rigidity of the ball rolling over this cavity is suppressed in the formula (8). To simulate the harder zone, stiffness of the ball rolling over that zone is increased by additional rigidity. This operation is done over time $\delta \tau$ corresponding to time defect duration as shown in Figure 14.

The parametric formula becomes as follows:

$$
K_{r r}^{(D)}(\gamma)=\sum_{i=1}^{m}\left[\delta_{1}(\tau)\left[K_{r r}^{(b)}+\delta_{2}(\tau) K_{d}(\tau)\right] / \cos \left(\gamma_{i}-\phi\right) /\right]
$$

where: $K_{d}(\tau)$ is the additional stiffness resulting from harder zone, $\delta_{1}(\tau)$ and $\delta_{2}(\tau)$ are respectively partial contact rupture parameter or switch $(0,+1)$ and additional stiffness switch $(0,+1)$. The two parameters are activated when the alignment of the defect with the balls will occur, $\tau$ is the defect duration event according to the bearing kinematics and shock time span $\delta \tau$.

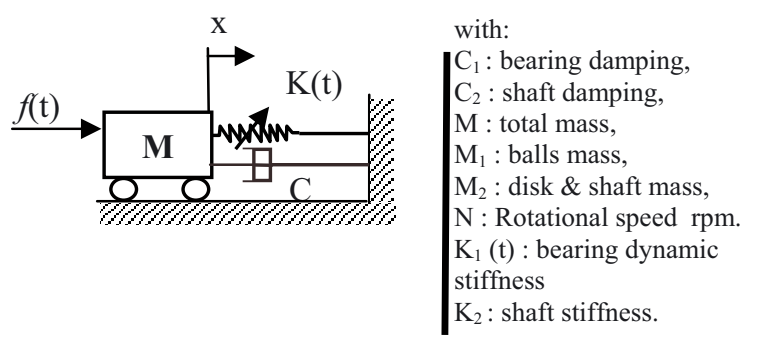

Fig. 11. Bearing calculation dynamic model of one DOF.

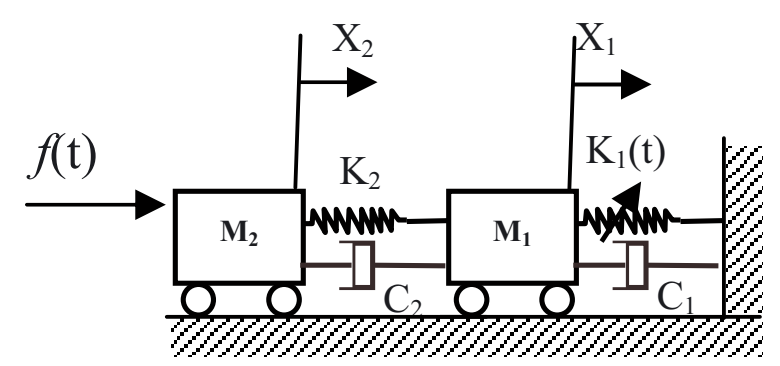

Fig. 13. Symmetric bearing calculation dynamic model of two DOF.

\section{Partial contact technique}

This technique considers that when the ball crosses the defect, it has no contact with rings of this ball. That is a rupture of contact. Partial means that the other balls stay in contact with ring.

\section{Imposed displacement technique}

Example illustrated in Figure 14c shows that it is not all the defects which are modelled from the stiffness formula, other methods exists; for example by introducing an imposed displacement into the motion equation resolution at each occurrence of ball rolling over a defect. The following illustrates the imposed displacement case.

$$
X_{i}=X_{i}+r_{i}
$$

with: $r_{i}$ simulating the imposed shaft displacement at the bearing, it depends on the defect size and position which is influenced by the load level as shown in Figure 9. The corresponding expression is:

$$
r i=\left|r_{0} \cos \left(\varphi_{d}-\phi\right)\right|
$$

where: $r_{0}$ is the bump size and $\varphi_{d}$ its position.

In addition, Equation (11) can be enriched and improved by introducing corrector parameters on the geometrical, mechanical and/or kinematics variables in basic formulas. 


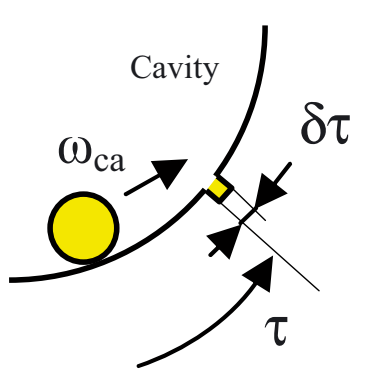

(a)

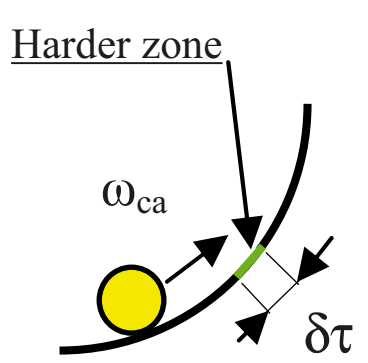

(b)

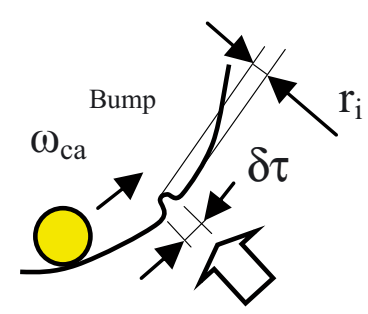

(c)

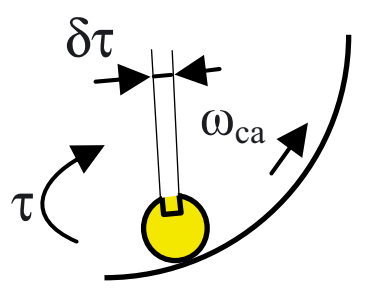

(d)

Fig. 14. Characteristic ball bearing defects simulation examples. (a) the ball rolls on a cavity inducing a partial contact rupture followed by a shock [1], (b) the ball rolls on harder zone, causes for example by an overheating, the stiffness becomes harder, (c) the ball rolls on a bump causing an imposed displacement $\left(r_{i}\right)$, (d) the roll of a ball having defect of cavity.

\subsection{Bifurcation and lubrication}

The problem of stability is investigated according to Pasynkova work [32]. To have a similar approach, the mechanical system was extended, in order to consider two degrees of freedom (vertical and horizontal displacements). Rotation occurs at constant spin. Viscous external (ball) and internal (oil-film) damping are considered.

To take into account lateral displacements, stiffness $K_{z z}$ and $K_{z r}$ issued from formula (8) are introduced. $K_{z z}$ is obtained from both left and right sides of balls (green area in Fig. 4a)

$$
\begin{aligned}
\frac{1}{k_{z z}(\gamma)}= & \frac{1}{\sum_{i=1}^{o} K_{r r}^{(b i)}\left|\sin \left(\gamma_{i}-\phi\right)\right|} \\
& +\frac{1}{\sum_{i=o+1}^{m} K_{r r}^{(b i)}\left|\sin \left(\gamma_{i}-\phi\right)\right|}
\end{aligned}
$$

with : $o$ number of balls in right part, $o \approx(m / 2)$

$K_{z r}$ is defined by considering lateral displacement due to radial force $F r . K_{z r}$ is calculated as follows:

$$
\begin{aligned}
\frac{1}{k_{z r}(\gamma)}= & \frac{1}{\sum_{i=1}^{o} K_{r r}^{(b i)}\left|\cos \left(\gamma_{i}-\phi\right) \sin \left(\gamma_{i}-\phi\right)\right|} \\
& +\frac{1}{\sum_{i=o+1}^{m} K_{r r}^{(b i)}\left|\cos \left(\gamma_{i}-\phi\right) \sin \left(\gamma_{i}-\phi\right)\right|}
\end{aligned}
$$

The damping force $F_{i}$ due to the oil-film [32] has two quantities; one term is proportional to velocity and the second to displacement. This last term is the source of instability. The force is expressed [32] as follows:

$$
F_{i}=-C_{i}(\dot{S}-i \omega S)
$$

where: $C_{i}$ is the oil film damping, $S=r+i z$ complex variable, $\{r, z\}$ coordinates and $\omega$ : spin speed of rotor.

To introduce this force into equation (9), formula (16) must be converted into vectorial form and formula (9) adapted for a system of two degrees of freedom described

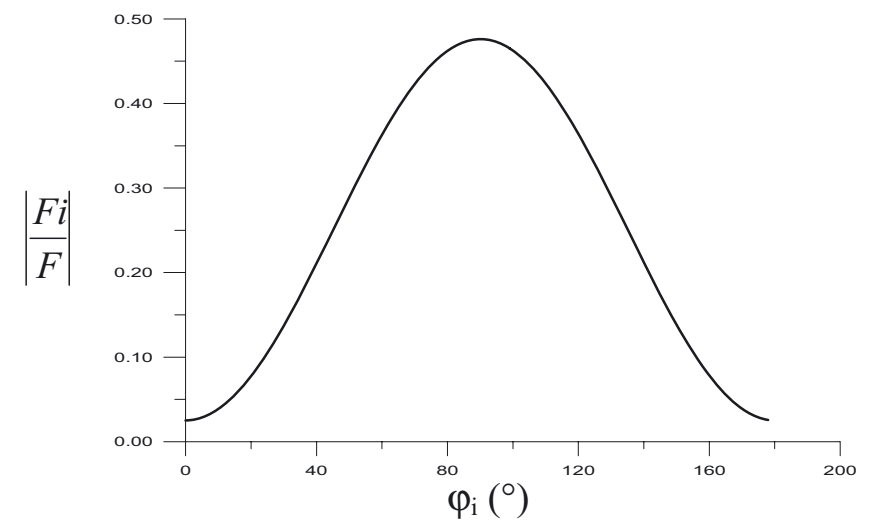

Fig. 15. Variation of the $F_{i}$ force applied to $i$ th ball.

into $(o, r, z, x)$ reference. After reducing, formula (9) becomes:

$$
\begin{gathered}
{\left[\begin{array}{ll}
m & 0 \\
0 & m
\end{array}\right]\left\{\begin{array}{l}
\ddot{r} \\
\ddot{z}
\end{array}\right\}+\left[\begin{array}{ll}
C^{\prime} & 0 \\
0 & C^{\prime}
\end{array}\right]\left\{\begin{array}{l}
\dot{r} \\
\dot{z}
\end{array}\right\}+\left[\begin{array}{ll}
k_{r r} & k_{r z} \\
k_{z r} & k_{z z}
\end{array}\right]\left\{\begin{array}{l}
r \\
z
\end{array}\right\}=} \\
\left\{\begin{array}{l}
f_{r} \\
f_{z}
\end{array}\right\}-\omega\left[\begin{array}{lr}
C i & 0 \\
0 & -C i
\end{array}\right]\left\{\begin{array}{l}
z \\
r
\end{array}\right\}
\end{gathered}
$$

with : $C^{\prime}=\left(C+C_{i}\right)$.

\section{Results}

A series of tests on the developed model was done. Firstly the static radial stiffness is calculated, under variable loads on bearing type FLT ISKRA $6203 \mathrm{Z}$ and then the dynamic stiffness is calculated according to the balls positions and the load level according to the load vector direction Figure 1.

\subsection{Preliminary results}

Static stiffness of one ball is calculated according to Palmgren's formula and load distribution as seen in Figure 9. The load on each ball is calculated from formula 5 and the resulted load distribution is illustrated in Figure 15. 


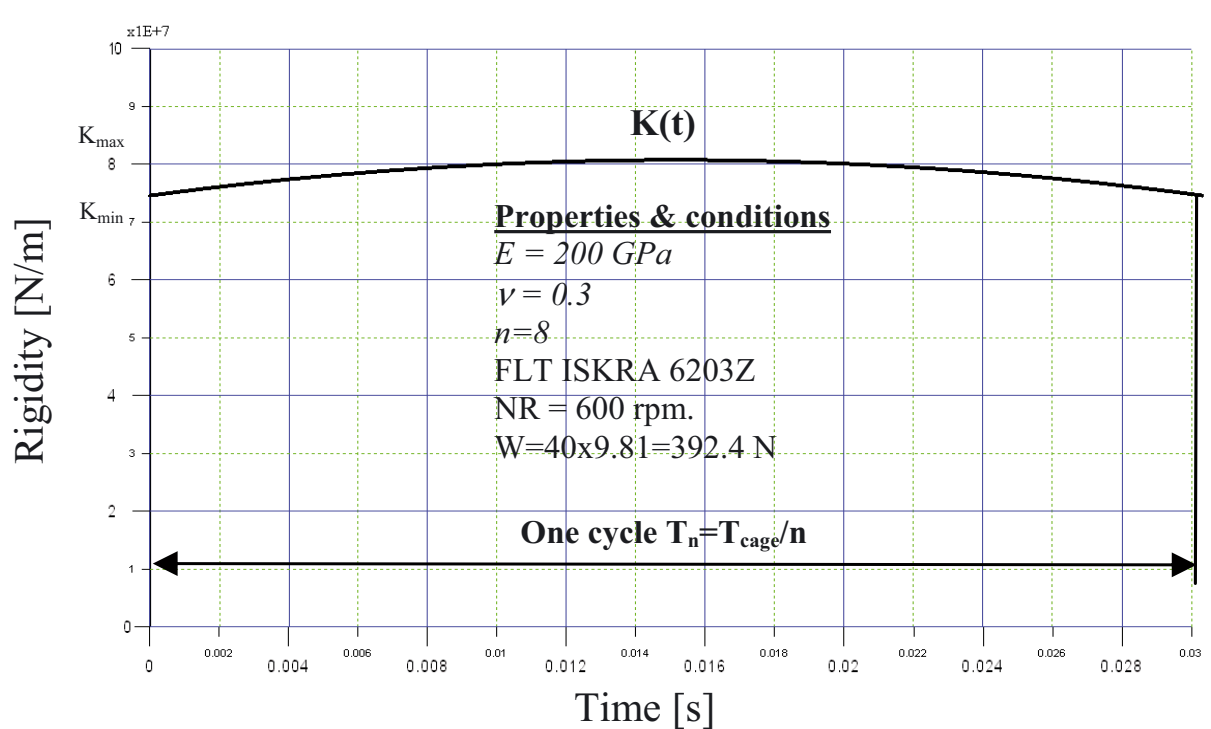

(a)

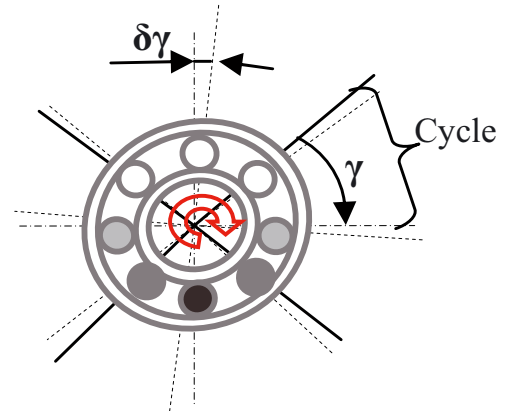

(b)

Fig. 16. (a) Dynamic bearing stiffness $K(t)$ for one cycle of $\gamma\left[0, \varphi_{n}\right]$. (b) Bearing rotation corresponding to one cycle of stiffness calculation.

The graph of Figure 15 represents the loading applied to a ball upon its position in the bearing and the vector load direction fixed at $90^{\circ}$. Noting that graph $14 \mathrm{~b}$ shows that the ball in loading axis is the most loaded. The ball stiffness is calculated with consideration of the $\left|\frac{F i}{F}\right|$ ratio, where $F=W$.

Figure 16a represents the graph of the stiffness time variation. To obtain $K(t)$, it is sufficient to compute the stiffness according to formulas $(7,8)$ by respecting the kinematics laws.

Dynamic stiffness curve, as shown in Figure 16a, indicates the nonlinear form. That is caused, principally, by the balls scrolling during rotation. Indeed, for one cycle Figure 16b, the balls change positions as seen in Figure 8 which generates a parabolic stiffness curve shape.

In order to highlight the principle appearance of defects and compare to known results [33-36] considered in this work as standards, some experiments are realized using the dynamic model of one degree of freedom. Test conditions are fulfilled at a speed of $600 \mathrm{rpm}$, a loading mass of $40 \mathrm{~kg}$ and damping ratio of 0.06 .

Figure 17 represents the bearing temporal responses without defects, showing deformation. The method used is based on the dynamic stiffness calculation of Figure 16a followed by the resolution of the nonlinear equation of motion (9) at equilibrium position as shown in Figure 5.

It is seen that curve shape has three waveforms, which corresponds to three characteristic phases of the positioning modes (Fig. 8).

The following figures illustrate several examples effects of characteristic defects application on the bearing.

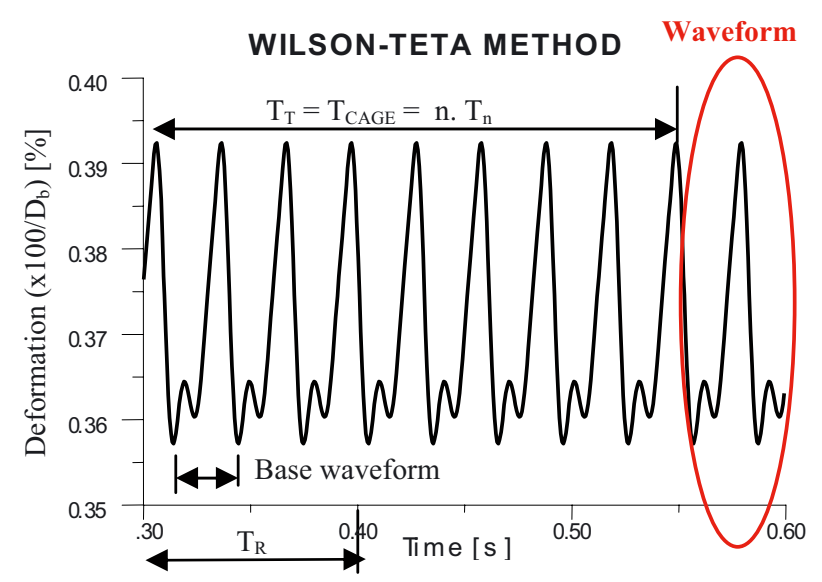

Fig. 17. Dynamic deformation without defects.

For a bearing of a size defect of $1 \% \varphi_{n}$, length is:

$$
\begin{aligned}
L_{\text {ext }}= & \left(\frac{2 \pi}{n} R_{\text {ext }}\right) \frac{1}{100}=0.16 \mathrm{~mm} \\
& =>\text { Defect Length on outer race } \\
L_{\text {int }}= & \left(\frac{2 \pi}{n} R_{\text {int }}\right) \frac{1}{100}=0.14 \mathrm{~mm} \\
= & >\text { Defect Length on inner race. }
\end{aligned}
$$

Figures 18 and 19 illustrate the emergence of effect of one cavity defect in velocity response for each occurrence of ball rolling over defect. The first one on outer raceway is characterised by a periodical pulse and the second on inner raceway is characterised by a signal modulation. In this case, assuming $\delta_{1}=0\left(\& \delta_{2}=0\right)$ at each occurrence 


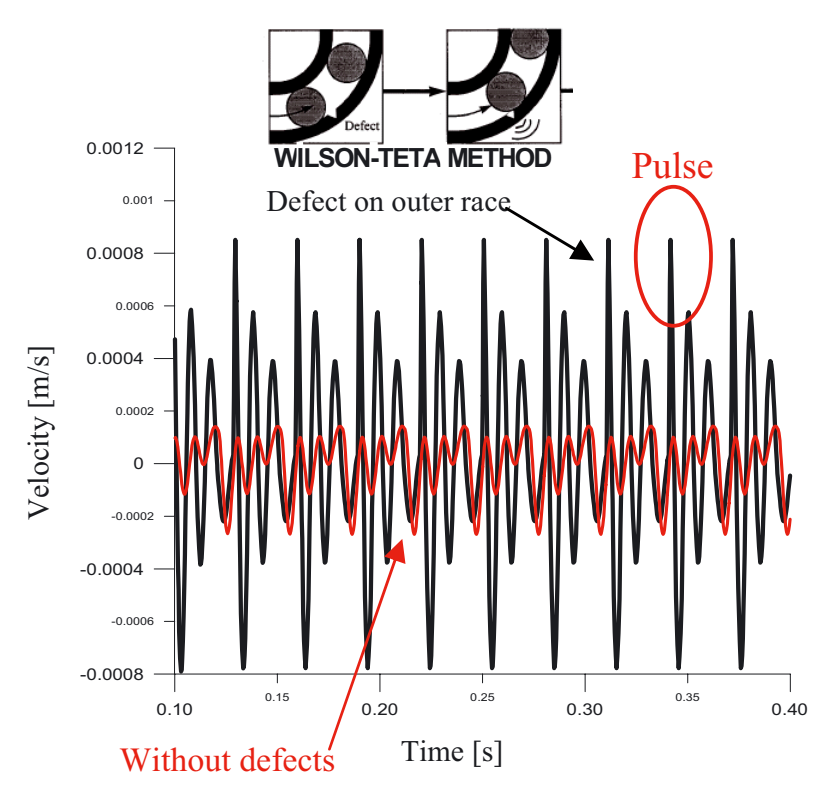

Fig. 18. Defects on the outer raceway.

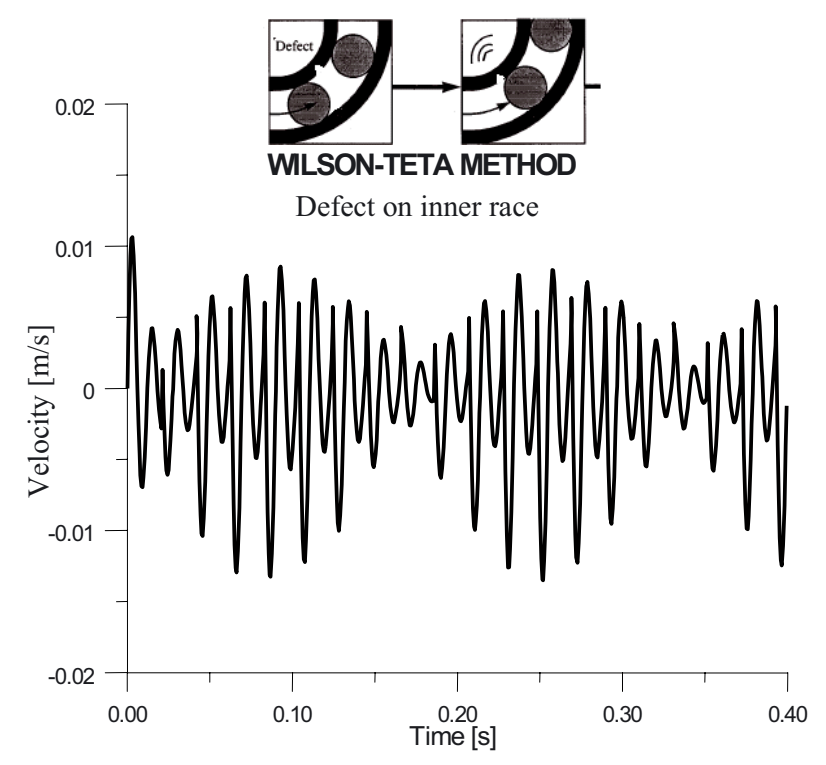

Fig. 19. Defect on the inner raceway.

with a period $(t=\tau)$. The time duration of defected area crossing is $(\delta \tau)$.

One can notice that the pulses are modulated as shown in Figure 19. The modulation is associated to the relative speed of the inner ring as referred to cage rotation (balls scrolling). It is due to position variation of defect area from sector (3) of most loaded ball section Figure 9. Whereas, in Figure 18, the defect has a fixed position, the signal presents identical and successive pulses. The period between pulses is equal to the time of two successive balls crossing the defect. The amplitude having a constant value is relative to the position of defect as compared to most loaded balls. Moreover, the pulse number for one revolution is more important in Figure 19 than

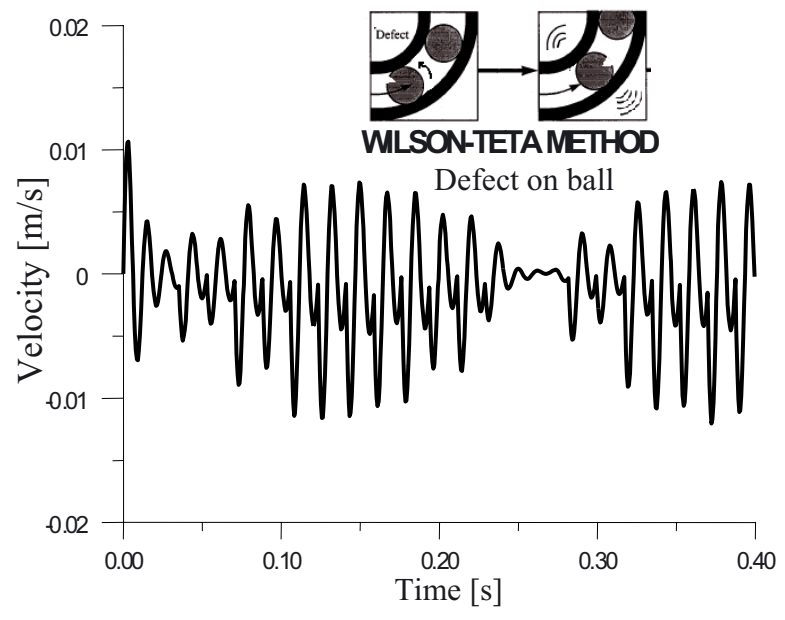

Fig. 20. Defect on the ball.

in Figure 18. This variation is caused by the difference between cage and inner ring rotation speed.

Simulation of one cavity defect on a ball is illustrated in Figure 20.

Figure 20 shows pulses modulation. It is related to the relative rotation speed of the ball as referred to cage rotation. In ordinates, it is due to position variation of defect area from most loaded ball section and successive contact with inner and outer rings respectively.

The comparison of the curves response of the different defects simulation as showed previously to some references as [33-36] gives good similarities.

\subsection{Spectral illustration}

The bearing characteristic frequencies related to the various defects on the bearing components could be written as follows [37]:

$$
\begin{aligned}
\mathrm{BPFO} & =\frac{n}{2} f r\left(1-\frac{d_{b}}{d_{p}} \cos \beta\right) \\
\mathrm{BPFI} & =\frac{n}{2} f r\left(1+\frac{d_{b}}{d_{p}} \cos \beta\right) \\
\mathrm{BSF} & =\frac{1}{2} \frac{d_{p}}{d_{b}} f r\left[\left(1-\left(\frac{d_{b}}{d_{p}} \cos \beta\right)^{2}\right]\right. \\
\mathrm{FTF} & =\frac{1}{2} f r\left(1-\frac{d_{b}}{d_{p}} \cos \beta\right)
\end{aligned}
$$

With: $f_{r}$ : FO ou RPM : rotating frequency $=$ revolutions per minute, $d_{\mathrm{b}}$ : ball diameter, $d_{\mathrm{p}}$ : bearing pitch diameter.

The following figures illustrate the spectrum of the velocity issued from Figure 18. The graphs are represented according to the ratio of the frequencies $(f)$ to the rotational speed frequency $\left(f_{o}\right)$.

Figures 21a and 21b illustrate the spectral distribution of outer raceway defect. This result has good similarities with Barkov results [38,39]. 

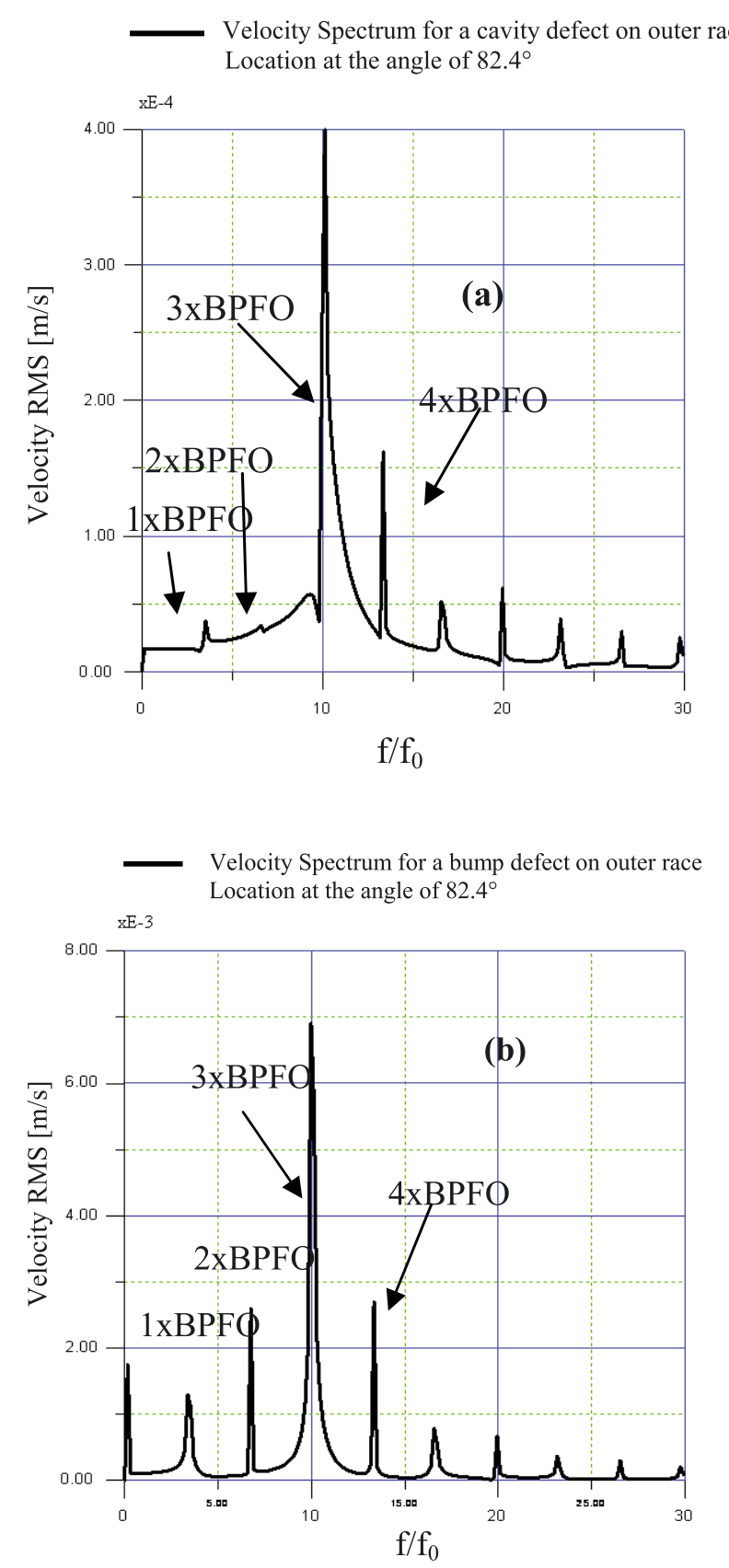

Fig. 21. (a) Velocity spectrum for a cavity defect on the outer raceway. (b) Velocity spectrum for a bump defect on the outer raceway.

Figure 21b (bump case) gives a better representation of the peaks compared to Figure 21a (cavity case), knowing that the bump case is modelled using the imposed displacement technique and cavity defect is modelled by the partial contact technique. The first technique introduces directly the displacement pulse while the second one generates the pulse after resolving the motion's equation under rigidity change effect, the pulse is then influenced by the position of defect and load level. Hence, the pulse is less consistent than in the first case, signal pulse being more quantifiable in the first technique by Fast Fourier

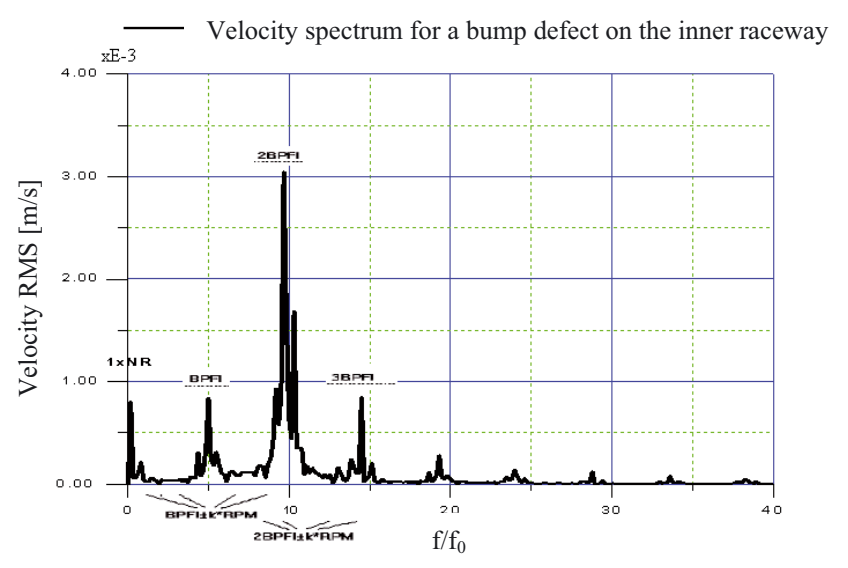

Fig. 22. Spectral response of a inner raceway defect.

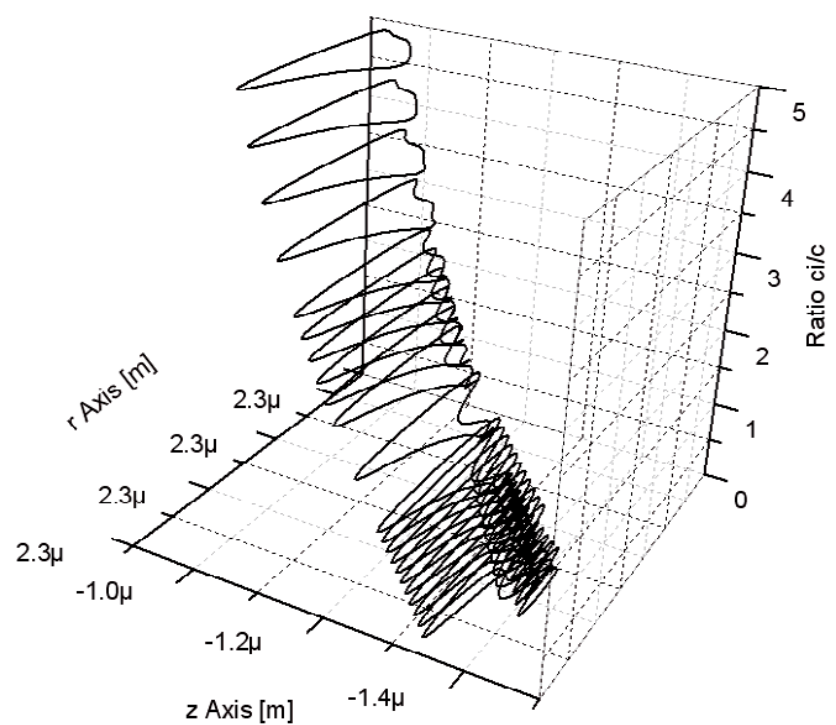

Fig. 23. Orbit under oil-film damping effect from 2 to 37 revolutions.

Transform (FFT) and gives then a better spectral representation.

Figure 22 represents the spectrum response of a bearing having a one cavity defect on the inner raceway. The spectral distribution is in conformity with Barkov results $[38,39]$ in this figure rolling element bearing with deep cavity on inner race friction surface.

\subsection{Bifurcation and lubrication results}

In this part, interest is focused on studying oil-film and spin speed effects on the dynamic behaviours of the ball bearing. The orbital evolution, phase trajectory and Poincaré section seem to be the best ways to use.

For the same type of ball bearing FLT ISKRA 6203Z and under the same conditions; speed is $1000 \mathrm{rpm}$. and initial conditions : $r(t=0)=r_{0}$ and $z(t=0)=0$, a number of tests are done. 

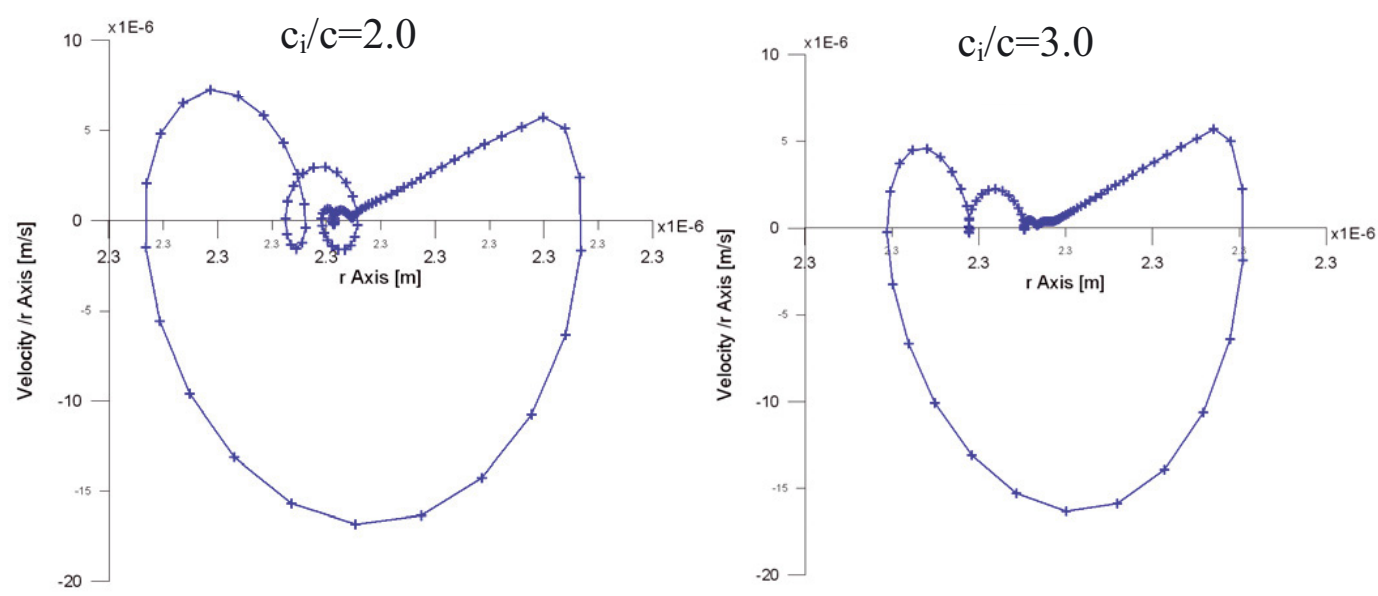

Fig. 24. Phase trajectory from 2 to 37 revolutions under oil-film damping variation effect.

\subsubsection{Oil-film damping effect}

To study the oil-film damping $\left(C_{i}\right)$ effect, a ratio of this one to the ball bearing one $(C)$ is introduced, this ratio $\left(C_{i} / C\right)$ changes from zero to 5 with a variable step of 0.1 .

Results of orbital evolution and phase trajectories of radial displacement are presented after the transitory phase, when permanent regime is reached, as in the following figures.

In Figure 23 when $\left(C_{i} / C\right)$ reaches the value 2.8, the orbit shape changes the form; the initial loop have one or more connexions points changed after to a semi-elliptic loop. Figure 24 of phase trajectories shows that after this value, internals loops disappear and there is a shifting of connexions over zero axes. This value of orbit modification can't be considered as bifurcation; because in all situations the orbit is stabilized on a limit cycle except that the form changes significantly. On the other hand, no instable situation was found.

Consequently, the bifurcation point is out of selected range of the oil-film damping ratio even the possible widest range was chosen.

\subsubsection{Spin speed variation effect}

The study of the spin speed consists to change speed from 50 to $5000 \mathrm{rpm}$. with a variable step of 100 to 500 .

Results of orbital evolution and phase trajectories of radial displacement are presented after the transitory phase, when permanent regime is reached, as in the following figures.

Figure 25 does not show a notable variation of orbit evolution, the loops stabilize on a limit cycle, except a significantly change from a flat form to a semi-elliptic one is seen. This change is confirmed in Figure 26 of phase trajectories by the disappearance of the internals loops and the shifting of connexions over zero axes when the speed exceeds $1000 \mathrm{rpm}$. The same result is obtained for bifurcation as previously.

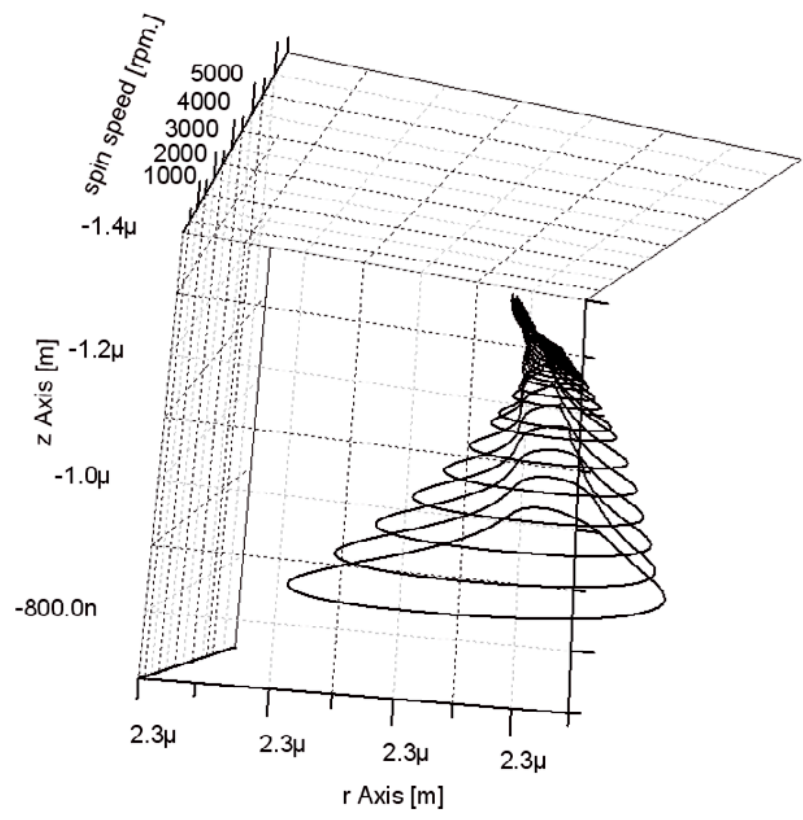

Fig. 25. Orbital under spin speed variation effect.

Figure 27 illustrates the effect of revolutions number on the orbit evolution for the case $\left(C_{i} / C\right)$ equal to 3 and spin speed equal to $1000 \mathrm{rpm}$.

Figure 27 shows that the orbit is stabilized on a limit cycle (colored blue) after transitory phase of approximately one revolution (colored red), the equilibrium point migrates, during this phase, from the static equilibrium position to the dynamic one (represented by the orbit center). In fact, the system reaches the permanent regime, $p>p_{b}$; where $p_{b}$ is the bifurcation point. Poincaré section confirms this observation.

\subsubsection{Comparison to a model of five degrees of freedom (5 DOF)}

To compare the results to those of A. Liew [40], single bearing model of Liew (5 DOF) is chosen. The model's 

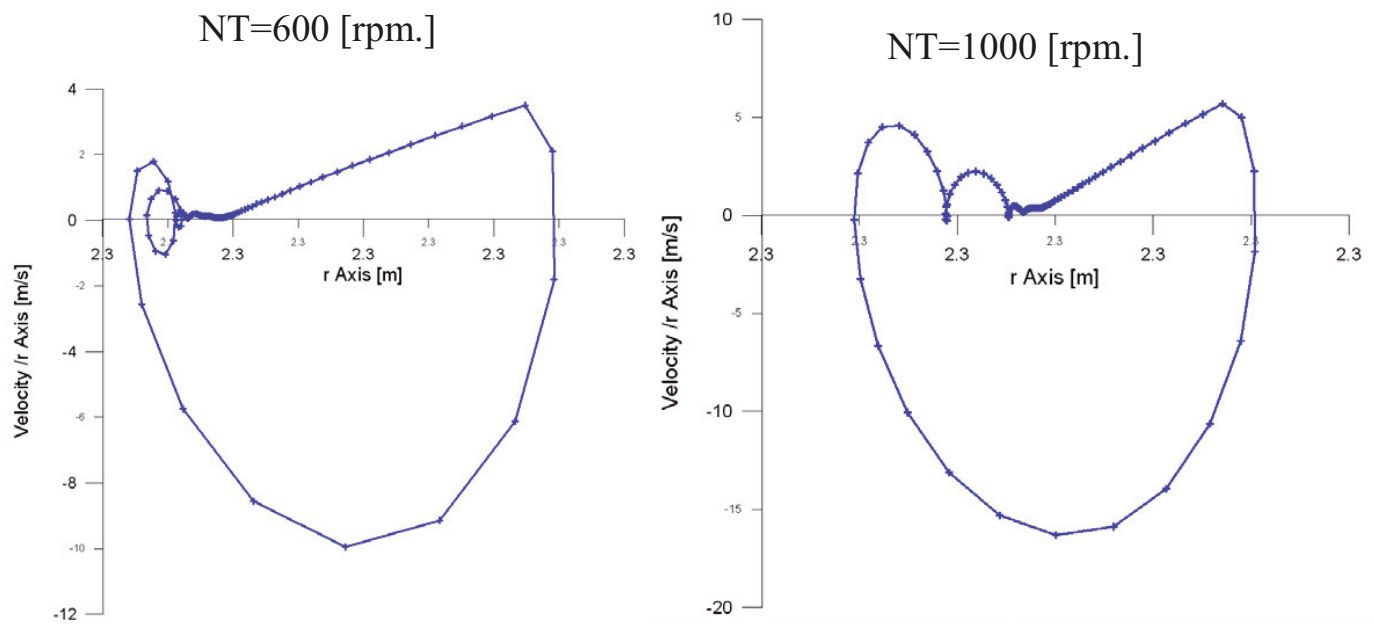

Fig. 26. Phase trajectory from 2 to 37 revolutions under spin speed variation effect.

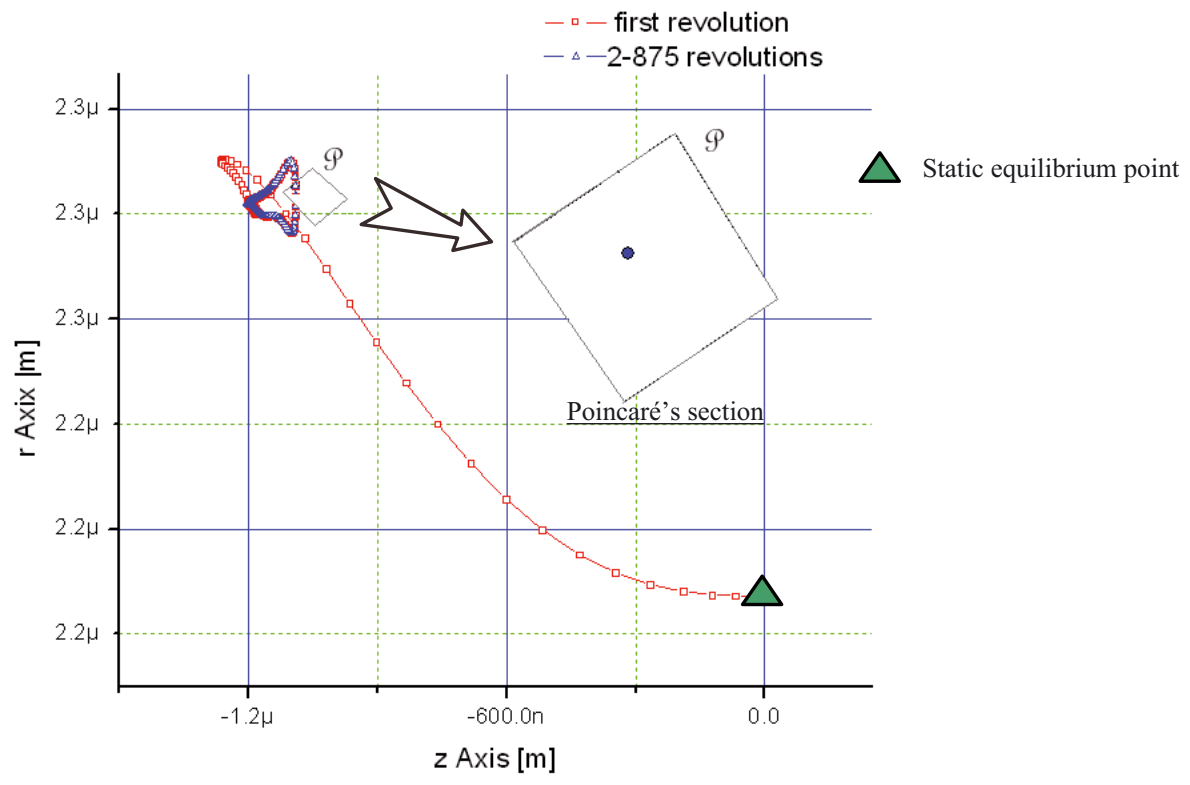

Fig. 27. Migration of equilibrium point and "Poincaré's section".

proprieties and conditions are: a ball bearing of type NSK/RHP with angular contact 7908CTDULP4, the rotor is supposed to be a simple masse of $2 \mathrm{~kg}$, the selected speeds are $10000 \mathrm{rpm}$ and $18000 \mathrm{rpm}$ and the angular contact is $15^{\circ}$. The lubrication is not considered.

To make a better comparison, it is necessary to use the same approach: redo the study of effect of introducing rotational inertial forces of balls masse. The inertial forces according to Liew's [40] are illustrated as follow:

Where $F_{\mathrm{e}}$ and $F_{\mathrm{i}}$ are the contact forces on outer and inner race, and $m_{\mathrm{b}}$ the ball mass.

Results of orbital evolution and phase trajectories of radial displacement are presented after the transitory phase and permanent regime are set, as in the following figures.

Figure 29 shows four results. (a) The orbit resultant of our model without inertia effect, it has relatively a

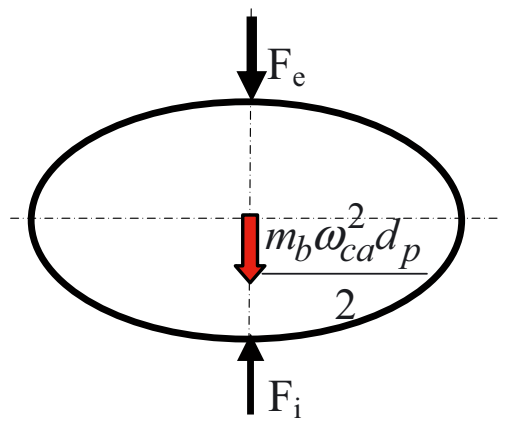

Fig. 28. Rolling element free body diagram [40].

very small size confounded to a point (red plus). (b) The orbit resultant of our model with inertia forces effect is 

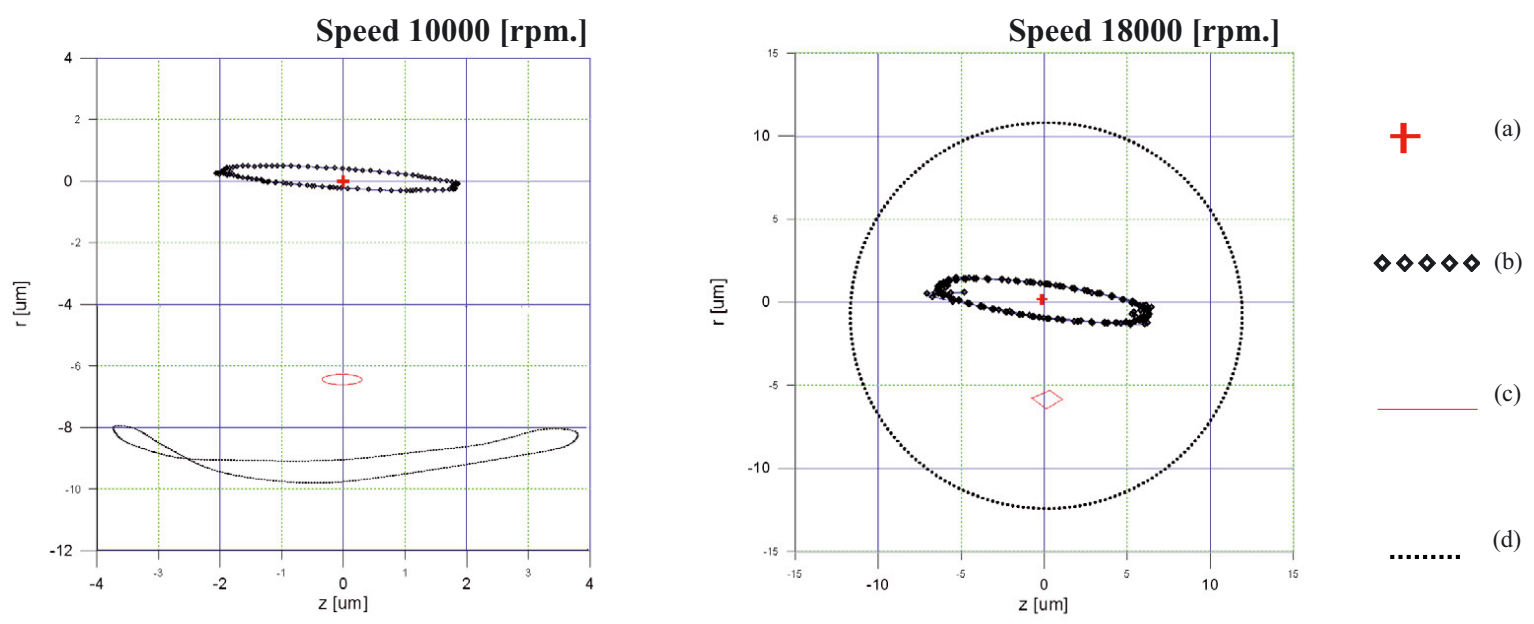

Fig. 29. Orbital evolution under inertial forces change.

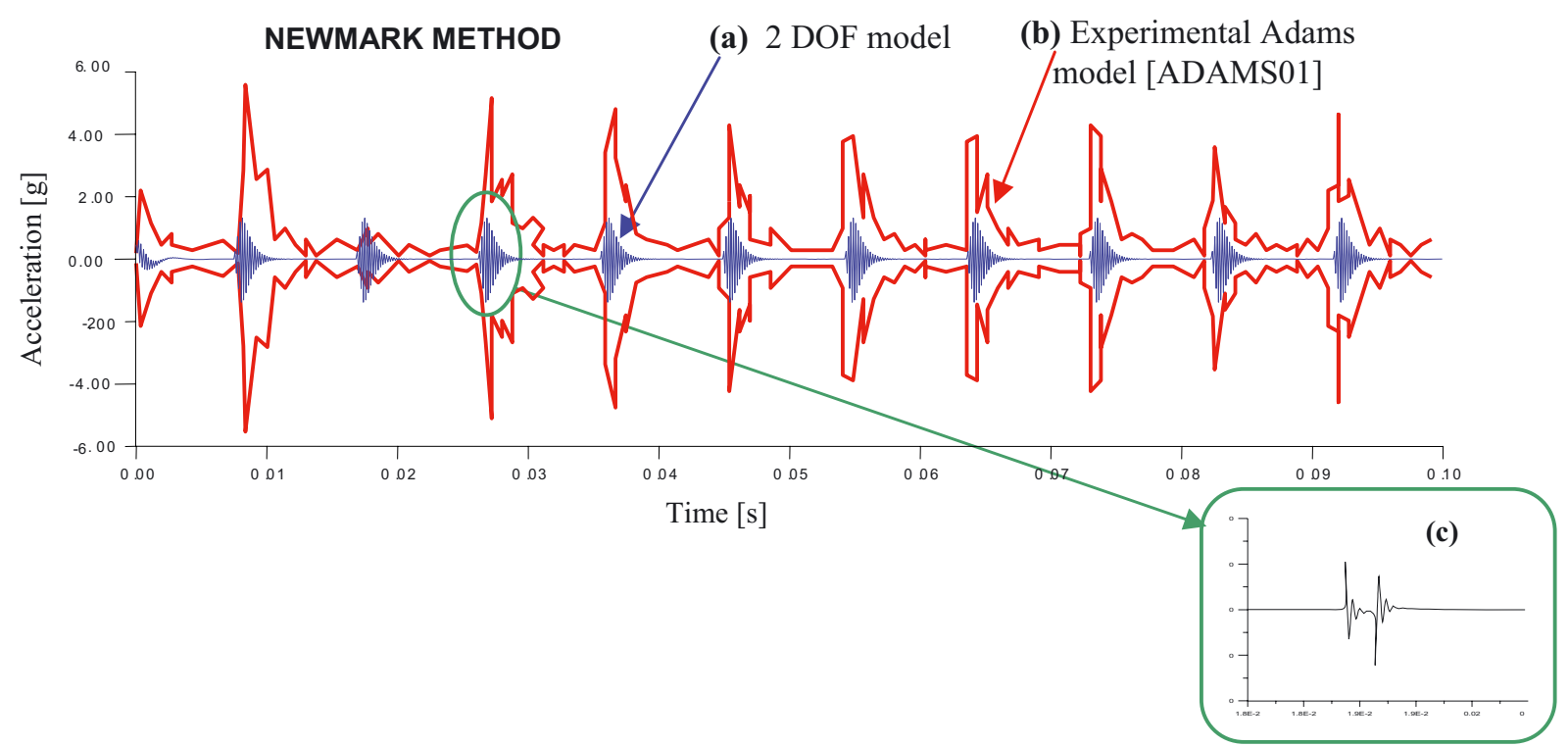

Fig. 30. Comparison of envelope results for an outer raceway 0.007 inch size fault, (a) 2 DOF model Figure 13, (b) experimental Adams model [17], (c) zoom on the pulse of our model (with a smaller step $\Delta T$ than in (a,b)).

illustrated with elliptic curves. (c) Liew's orbit without inertia and (d) the Liew's orbit with inertia.

Curves indicate that inertia force has an important effect on the ball bearing dynamic behaviours. But differences exist between the two models; like:

- orbital centers on $(r)$ axis are different for a speed less than $1100 \mathrm{rpm}$;

- orbital shapes are different.

The principal reason of this dissimilarity is that Liew's model considers a preloaded balls, whereas, our model consider only one half of balls loaded; this causes an anisotropic effect as shown in Figure 29b.

\subsection{Time vibration response envelope illustration for defect simulation}

The Adams induction motor [17] is modelled by a special shaft supported on two rolling bearings. This model is similar to that of 2 DOF (Fig. 13).

Figure 30 illustrates the Adams experimental results [17] on a bearing SKF 6205 (with 9 balls) with a shaft diameter of $25 \mathrm{~mm}$ (0.9843 inch), a rotational speed of $1797 \mathrm{rpm}$, a total mass of $4.1 \mathrm{~kg}$, a shaft length of $0.2032 \mathrm{~m}$ and a viscous damping of 0.4 between balls and raceway (damping ratio 0.001), rotor damping ratio of 0.035 and housing damping ratio of 0.027 .

It proves that envelopes comparison gives acceptable correspondence between our model results and those of experimental and numerical Adams model; in fact, good similarity is found, in time and amplitudes which are close 
(a) 2 DOF model

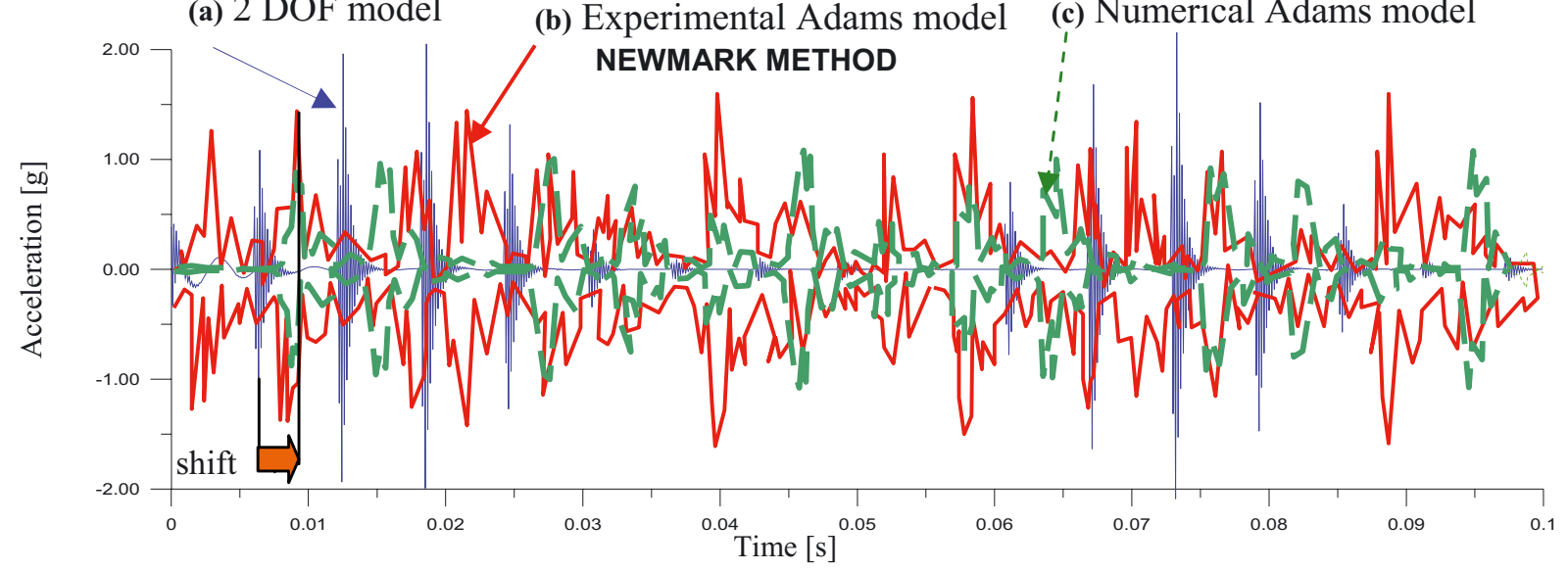

Fig. 31. Comparison envelope results of three models for an inner raceway 0.007 inch size fault (a) our model with 2 DOF, (b) experimental Adams model and (c) numerical Adams model [17].

to each other. Our model has two successive pulses due to the cavity crossing (from start to end), Figure 30c. On the other hand, the frequency rating $1 \times \mathrm{BPFO}(106 \mathrm{~Hz})$ is similar to that found by Adams [17].

Figure 31 represents a comparison of envelope results of three models corresponding to inner raceway fault. The results of our model (a) are represented with blue color. The experimental (b) and numerical (c) results of Adams [17] are represented respectively with red and green color.

An acceptable correspondence is found between envelopes but there is a slight shift (see Fig. 31). This shifting could be explained by the difference of defect positions on raceway between models. In our model, defect is located at $87^{\circ}$. On the other hand, our results are more similar to numerical results then Adams' experimental ones. The frequency rating $1 \times$ BPFI $(162 \mathrm{~Hz})$ is similar to that found by Adams [17].

The period of Adams' waveform is greater then our model's; among the reasons is Adams [17] consideration of the housing damping.

The 2 DOF model presents a modulation which is due to the variation of defect position from loading line, whereas this modulation is slightly perceptible in the Adams results. This is due, firstly, to the consideration of only one half of the balls is loaded, secondly, to the effect of experimental and numerical considerations that Adams adopted, and finally, to the simplifications taken in our model.

In conclusion, the envelope comparison gives similarities, judged acceptable, for simulation applications. The method of defect simulation is rather alike Adams' one; Indeed, Adams method simulates the defect (Fault) by adjusting the inner and/or outer raceway diameter for each element (ball) rolling on fault. However, the Adams model presents a heavy formulation and it doesn't simulate the defect on ball element.

The numerical model of Kiral [41, 42] including a rolling bearing and its housing structure is submitted to the effect of a rotating loading vector. The studied bearing is 6205 model with single row deep groove ball bearing and has an external diameter of $52 \mathrm{~mm}$, internal diameter of $25 \mathrm{~mm}$, a ball diameter of $8 \mathrm{~mm}$, contact angle $\beta=0^{\circ}, 9$ balls, a damping ratio of 0.005 and a total mass of $1.8213 \mathrm{~kg}$. The system presents a rotating loading vector with the rotational speed of $1000 \mathrm{rpm}[41,42]$.

To allow for a good comparison, three significant modifications have been introduced to our initial model (Figs. 5 and 7): the load vector becomes rotating, the lateral rigidities are introduced and the model of loading will extend to more than half of the balls (Fig. 32).

The transformation $[T][k]\left[T^{t}\right]$ is used to calculate $K_{z z}$ and $K_{y y}$, where $\left[K_{r r}\right]$ is a polar matrix of one element, to illustrate one defect only, the obtained stiffness $K_{z z}$ and $K_{y y}$ are:

$$
\left\{\begin{array}{c}
K_{y y}(t)=K_{r}(t) \sin ^{2}\left(\omega t+\varphi_{0}\right) \\
K_{z z}(t)=K_{r}(t) \cos ^{2}\left(\omega t+\varphi_{0}\right) \\
\text { with } \omega \text { the rotational speed and } \varphi_{0} \text { initial } \\
\text { vector load position. }
\end{array}\right.
$$

The points $\mathrm{P} 1$ and $\mathrm{P} 3$ will have the same stiffness $k_{z z}$ and P2 will have $K_{y y}$ stiffness.

Figure 33 illustrates the results comparison of the defect on a ball and assuming that the ball rolls only around one axis. Measurement is made at the P2. The numerical results of Kiral $[41,42]$ are represented in red color, results of our model is represented in blue color.

The comparison of the two envelopes curves according to the amplitudes and time shows an acceptable trend. A slight shift exists between the two curves; because of different choices of defect position on ball. Whereas, the two curves present a comparable modulation, this is due to the variation of defect position from $h$ loading line and ball cage rotation.

In conclusion, the two models comparison shows a similarity, knowing that our results issued from only one degree of freedom model with a nonlinear dynamic stiffness compared to the Finite Element Model of Kiral. Those 


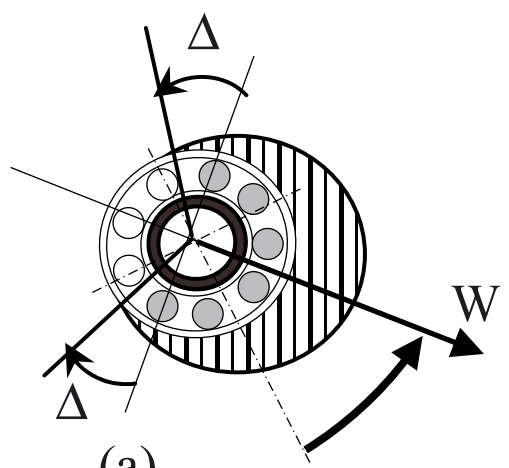

(a) (b)

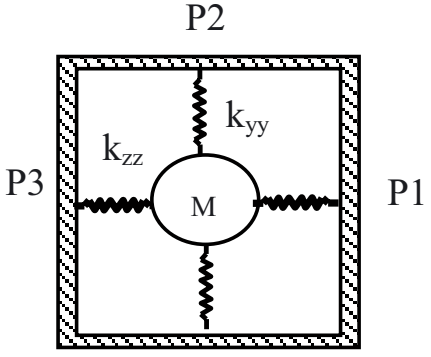

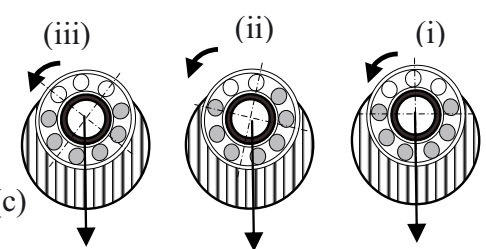

Fig. 32. One DOF Model adapted for the comparison with Kiral work. (a) Introduction of balls loading model, with an increase in the angular covering of $(\Delta)$ on both sides comparing to initial study case and the illustration of the revolving loading vector. (b) Introduction of the stiffness to the points P1, P2 and P3 in bearing modelling. (c) Effect of the balls odd number on the stiffness fluctuation (i) six balls loaded, (ii) seven balls loaded and (iii) six ball loaded.

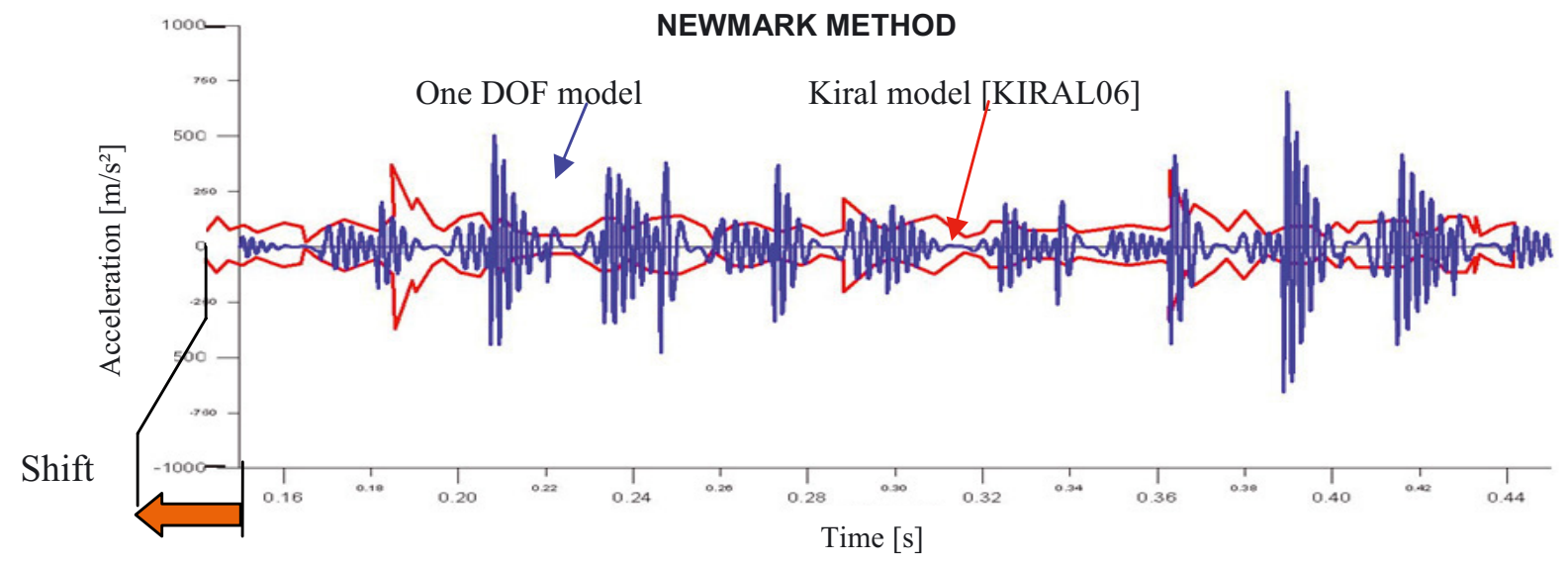

Fig. 33. Envelopes Comparison for a defect on the ball.

considerations and others can probably explain some little differences between Kiral's and our results. For example, the housing structural damping effect was not considered in our model. The defect simulation technique is satisfactory according to Kiral's results $[41,42]$ and to bearings kinematics laws. On the other hand, the method simulating the defect by imposed displacement technique with an equivalent defect size gives results close to those obtained by Kiral [42], knowing that Kiral introduces a special pulse, to simulate defect, dependent on several parameters like the radial force, the defect size, etc. In addition, this special pulse does not come from the intrinsic structural behaviours.

On the other hand, it proves in this case, that the type of the number of balls (even or odd) is important. Results show that during the cage rotation, there are two alternate cycle states: the case for an even number and the case for odd one of loaded balls. This situation causes the change of the stiffness amplitude, consequentially, the dynamic response is perturbed.

Abdullah Morhain's [43] model is a bearing with the following properties: external diameter $84 \mathrm{~mm}$, internal diameter $40 \mathrm{~mm}$, ball diameter $12 \mathrm{~mm}, \beta=0^{\circ}$ and 10 elements, the bearing is under a load of $4.47 \mathrm{kN}$ and the shaft turns at a rotational speed of $1000 \mathrm{rpm}$ to $2000 \mathrm{rpm}$. These properties are exploited by our model of a one degree of freedom.

The objective of comparison is to show importance advantage of the partial contact technique used in our model; remembering that our method creates two pulses ratings with the defect crossing (from beginning to end) Figure 30c; the period between the two pulses highlights the defect size. For an adequate damping and one defect on outer raceway with different widths $0.85 \mathrm{~mm}, 2.95 \mathrm{~mm}$, $7.12 \mathrm{~mm}$, the following results are found.

The comparison between the two models shows that ours can highlight a very small size of defects, whereas Morhain's one does not, probably because of noise.

Figure 34 illustrates the time of the defect crossing according to the imperfection length on the outer raceway. Our model can be useful as a tool to check the AE technique sensitivity.

Chao [44] studied the case of multiple defects effect on the outer raceway. In order to compare to our model, the 


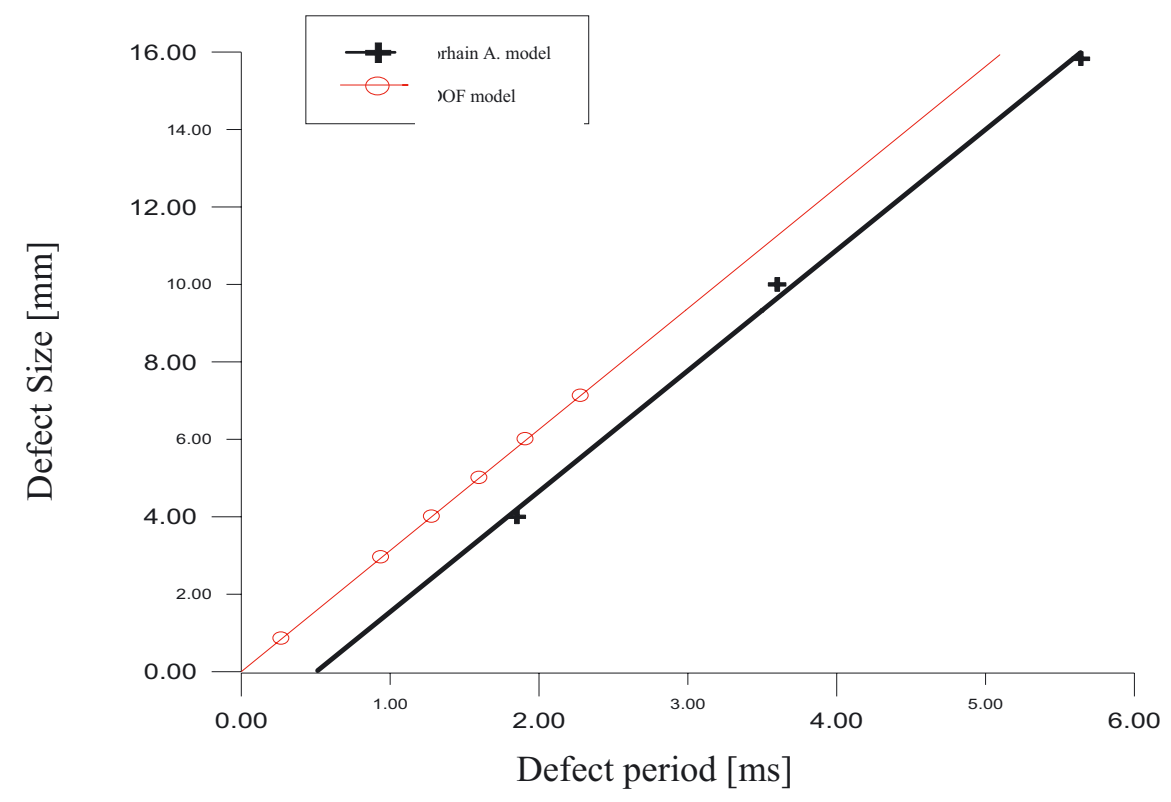

Fig. 34. Highlighted method sensitivity of the defect size detection.

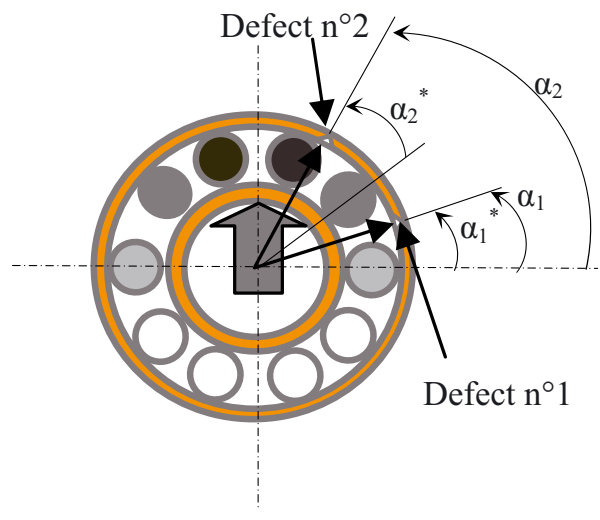

Fig. 35. Diagram illustrating the positions of the two cavities defects on the ball bearing outer raceway.

same type of bearing previously described is used. The bearing turns at a speed of $1800 \mathrm{rpm}$ with the presence of two cavities defects, the first one at position $18^{\circ}$ and the second at $73^{\circ}$ (Fig. 35).

Figure 36 relating to the pulses distribution due to the defects, shows that the pulsations are influenced by three fundamental parameters. The first one is the distance between defect and the most loaded balls (Figs. 4a and 35) which defines the pulse amplitude. The second is the relative position of the defect in the cage as referred to the nearest ball coming, which defines the phase shift $(\Delta \alpha)$ between the two defects pulses. The third factor is the size of the defect, which we have not considered here.

Phase shift $(\Delta \alpha)$ can be calculated by the following method:

$\alpha_{i}^{*}=\alpha_{i}-k_{i} \varphi_{n}$, where $k_{i}$ is a whole number $k i=$ $\alpha_{1} / \varphi_{n}, i=1,2 \Delta \alpha=\left|\alpha_{1}^{*}-\alpha_{2}^{*}\right|$ and $\Delta T=\omega_{\mathrm{ca}}(\Delta \alpha)$.

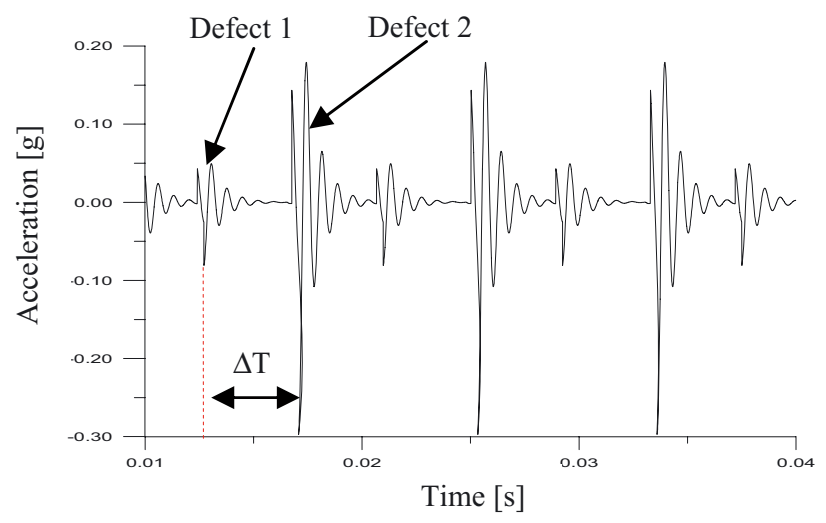

Fig. 36. Presence of two defects on the outer raceway.

In conclusion, these results show clearly the dephasing nature between the two pulses compared to Chao's work [44] and identify the number of defects using the propriety of amplitude variation.

\section{Conclusion}

The ball bearing study allows to obtain a mathematical nonlinear behaviour model with five degrees of freedom, this model permits calculating stiffness with a simple formula and introducing various bearings characteristic defect types.

The two methods of defect simulation, partial contact and imposed displacement, may complement each other and simulate major cases.

The procedure adopted to calculate the dynamic stiffness while using Palmgren's technique of deformation calculus, Rajab's technique of stiffness matrix elements 
calculus, our model of load and our dynamic model, these allow obtaining a parametric formula with acceptable characters of compactness and robustness.

A number of considerations are taken in our model: only half of balls are loaded, the loading line pass through one or between two balls, the rotating loading vector, the rotation of cage (scrolling), the level load and fault's simulation is resulted from rigidity parameterisation, all these are good arguments in order to consider our model.

The most important argument is the consideration of the defect as originating from intrinsic structural behaviours.

It is observed that balls number type (odd ore even) is important and interesting when only one part of balls is loaded.

The introduction of bifurcation, lubrication and inertia study gives more to our work. Results do not show clearly the bifurcation point; because of non consideration of the rotor behaviour, whereas lubrication and inertia effects have been satisfactorily illustrated.

Although our model is smaller and simpler when compared to some models of five, more or less degrees of freedom, found in literature, seems satisfied, it is noted also that comparisons to some experiment results could be considered as an experimental verification.

Acknowledgements. This research was done at the mechanical laboratory of the "Nuclear research center of Birine". The authors wish to thank particularly the reviewers of "Mécanique \& Industrie" review and Mr. Morsli Oumarni for their contribution in the English correction of this manuscript.

\section{References}

[1] L. Bourgain, R. Dart, J. Bourgain, Machines tournantes et circuits pulsés. Applications Industrielles et médicales de l'analyse spectrale, Dunod, Édition Bordas 1988, pp. $392-411$

[2] J.E. Shigley, L.D. Mitchel, Mechanical Engineering Design. 4th Edition, McGraw-Hill, 1983, pp. 85-88, pp. $484-514$

[3] S. Timoshenko, Résistance des matériaux, Théorie élémentaire et problèmes, tome I, 1968, collection Dunod technique, pp. 2-19

[4] A. Palmgren, Ball and roller bearing engineering, 3rd Edition, S. Burkank \& Co, Philadelphia, 1959

[5] T.A. Harris, Rolling Bearing Analysis, $3^{\mathrm{e}}$ edition, 1966, Lavoisier, 1991

[6] P. Eschmann, L. Hasbargen, K. Weigand, Ball and roller bearings, Theory, design and application, R, Oldenburg Verlag, John Wiley and Sons, Inc, 1985

[7] J. Kraus, J.J. Blech, S.G. Braun, In situ determination of roller bearing stiffness and damping by modal analysis. Trans. of the A.S.M.E., J. Vibration, Acoustics Stress and Reliability in Design 109 (1987) 235-240

[8] R.J. Drago, New approach for analysing transmission noise, Machine Design 52 (1980) 114-115

[9] M.D. Rajab, Modelling of the transmissibility through rolling-element bearing under radial and moment loads,
Ph.D. thesis, The Ohio state university, Columbus, Ohio, 1982

[10] W.B. Young, Dynamic modelling and experimental measurement of gear shaft and housing system, M.S. Thesis, The Ohio state university, Columbus, Ohio, 1988

[11] T. Lim, Chin, Vibration transmission through rolling element bearings in geared rotor systems, the Ohio State University, 1989, pp. 12-60

[12] J.M. De Mul, J.M. Vree, D.A. Maas, Equilibrium and associated load distribution in ball and roller bearings loaded in five degrees of freedom while neglecting friction. part I: general theory and application to ball bearings, Trans. of the A.S.M.E., J. Tribology 111 (1989a) 149-155

[13] S.E.H. Fukata, T. Kondou, T. Ayabe, H. Tamura, On the Radial Vibration of Ball Bearing, Bull. JSME 28 (1985) 899-904

[14] E. Yhland, A linear theory of vibrations caused by ball bearings elasticity in gear at moderate speed. Trans. Of the A.S.M.E., J. Tribology 154 (1992) 348-359

[15] I.S. Choi, Simulation des mécanismes complexes en C.M.A.O. étude des non linéarités de comportement. Application aux boîtes de transmission de puissance d'hélicoptères, Thèse de doctorat, INSA de Lyon, 1993 $\mathrm{n}^{\circ} .93$ ISAL, 0034, p. 224

[16] B. Adelin, Modélisation dynamique globale des boîtes de vitesses automobiles, thèse de doctorat à INSA de Lyon, 1997, n 97 ISAL 0084, pp. 23-42

[17] M.L. Adams, Analysis of Rolling Element Bearing Faults in Rotating Machinery: Experiments, Modelling, Fault Detection and Diagnosis, Thesis for Doctor of philosophy in the case Western Reserve University, August 2001, pp. 12-13, 25-28, 50-53, 74-108, 147-183

[18] B.T. Holm-Hansen, Development of self-diagnostic rolling element bearing, Thesis for Doctor of philosophy in the University of Massachusetts, 1999, pp. 12-30

[19] M. Lelkes, Définition des engrenages klingelnberg, Thèse de doctorat présentée à l'INSA Lyon, $\mathrm{N}^{\circ}$ d'ordre 02ISAL-0012, 2002. pp. 106-110, pp. 125-127

[20] F. Louf, Contact: théorie de Hertz, 2003, site Internet: http://agregb1.dgm.enscachan.fr/Documents / TheorieTP/files/Contact.pdf, pp. 1-7

[21] Chevalier, Guide du dessinateur industriel, Classique Hachette, Édition 1979, pp. 188-189

[22] M. Moret, Roulements et butées à billes et à rouleaux, Techniques de l'ingénieur, Vol. B5-I, août 1995

[23] A. Palmgren, Les roulements description, théorie, application, SKF Paris 1967, p. 120

[24] P. Estocq, Une approche méthodologique numérique et expérimentale d'aide à la détection et au suivi vibratoire de défauts d'écaillage de roulements à billes, thèse de doctorat, Université de Reims Champagne Ardennes, 2004, pp. $35-51$

[25] A. Allezy, Contribution à l'analyse du comportement dynamique de machines tournantes en régime transitoire, Approches métrique et expérimentale, Thèse de doctorat présentée à l'INSA Lyon, $\mathrm{N}^{\circ}$ d'ordre 2006-ISAL-0013, 2006, pp. 146-150

[26] M. Paz, Structural dynamics. Theory and computation, Van Nostrand Reinhold Company New-York, 1985 (2 Édition), pp. 389-397

[27] P. Ladevèze, J.-P. Pelle, Mastering Calculations in Linear and Nonlinear Mechanics, Translated by Theofanis 
Strouboulis, Mechanical Engineering Series Frederick F. Ling, Springer Science+Business Media, 2005 Inc., p. 250

[28] N.M. Newmark, A Method of Computation for Structural Dynamics, ASCE J. the Engineering Mechanics Division, 85 (1959)

[29] G. Baratto, J.J. Guerin, J. Mongis, C. Toupnies, A. Vieu, Analyse morphologique des défaillances d'organes de machine, CETIM 1992, pp. 58-65

[30] C.M. Harris, C.E. Crede, Shock and vibration Handbook, Second Edition, McGraw-Hill 1976, pp. 40-5-40-8

[31] C. Marcovici, J.-C. Ligeon, Utilisation des techniques de fiabilité en mécanique, PSI techniques et documentations, Paris, 1996

[32] I.A. Pasynkova, Bifurcations of Cylindrical Precessions of an Unbalanced Rotor, Technische Mechanik, Band 26, Heft 1, (2006), 1-10, Manuskripteingang: 12 Oktober 2005, pp. $1-10$

[33] M. Angelo, Vibration monitoring of Machines, Technical Review N¹-1987, Brüel \& Kjaer, pp. 11-31

[34] Brüel \& Kjaer, Surveillance des machines, révision Sept. 1990, pp. 19-33

[35] R.B. Randall, B. Tech, Frequency Analysis, 3rd edition, 1st print Brüel \& Kjaer 1987, pp. 179, 288-295, ISBN 87 87355078

[36] B.J. Trampe, Mechanical Vibration and Shock Measurements, Brüel \& Kjaer, avril 1984, pp. 197205

[37] C.M. Harris, A.G. Piersol, Harris'shock and Vibration Handbook, Fifth Edition, McGraw-Hill, 2002, 1996, 1988, 1976, 1961 by The McGraw-Hill Companies, Printed in the United States of America., pp. 16-10-16-11
[38] V. Barkov, N.A. Barkova, Non-linear Signal Models in Vibroacoustic Machine Diagnostics, 1996

[39] V. Barkov, N.A. Barkova, The Artificial Intelligence Systems for Machine Condition Monitoring and Diagnostics by Vibration, Published in the Proceedings of the Saint Petersburg Post-graduate Institute of the Russian Federation Power Industry and Vibration Institute, USA, Saint Petersburg, 1999, Vol. 9

[40] A. Liew, A study of a rotor system with ball bearing non-linearities; and the development of transfer matrix techniques suitable for analysing such systems, Thesis for Doctor of philosophy in New South Wales University, 2002, pp. 91-95

[41] Z. Kiral, H. Karagülle, Simulation and analysis of vibration signals generated by rolling element bearing with defects, Tribology International 36 (2003) 667-678, 669673

[42] Z. Kiral, H. Karagülle, Vibration analysis of rolling element bearings with various defects under the action of an unbalanced force, Mechanical Systems and Signal Processing 20 (2006) 1967-1991, 1971-1987

[43] A. Morhain Al-Ghamd, D. Mba, A comparative experimental study on the use of acoustic emission and vibration analysis for bearing defect identification and estimation of defect size, Mechanical Systems and Signal Processing 20 (2006) 1537-1571, October 2004, pp. 15381541,1546

[44] Chao-Shih Liu, Fault detection of rolling element bearings, Thesis for Doctor of philosophy in the University of Washington, 2005, pp. 96-98. 